\title{
Research Paper \\ Strategic Leadership and Its Role in Marketing Ambidexterity Prowess-An Exploratory Study of the Opinions of Workers in the Mosul Dairy
}

Journal of

\section{TANMIYAT AL- RAFIDAIN}

\section{(TANRA)}

A scientific, quarterly, international, open access, and peer-reviewed journal

Vol. 40, No. 132

Dec. 2021

(C) University of Mosul | College of Administration and Economics, Mosul, Iraq.

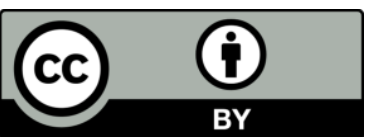

TANRA retains the copyright of published articles, which is released under a "Creative Commons Attribution License for CC-BY-4.0" enabling the unrestricted use, distribution, and reproduction of an article in any medium, provided that the original work is properly cited

Citation: Hassan, A. M., ALMulla Hasan, Mohammad M. H., (2021). "Strategic Leadership and Its Role in Marketing Ambidexterity Prowess-An Exploratory Study of the Opinions of Workers in the Mosul Dairy". TANMIYAT AL-RAFIDAIN, 40 (132), $37-60$,

https://doi.org/ 10.33899/tanra.2021.129904.10 85

P-ISSN: 1609-591X e-ISSN: 2664-276X tanmiyat.mosuljournals.com

\author{
Ahmed M. Hassan ${ }^{1 `}$ Mohammad M. H. AL-Mulla Hasan ${ }^{2}$ \\ ${ }^{1 \& 2}$ College of Administration and Economics /University of Mosul
}

Corresponding author: Ahmed M. Hassan, College of Administration and Economics /University of Mosul

94ahmed19@gmail.com

DOI: https://doi.org/ 10.33899/tanra.2021.129904.1085

Article History: Received:8/4/2021; Revised:1/5/2021; Accepted: 10/5/2021; Published: 1/12/2021.

\section{Abstract}

In their research, the two researchers sought to include a set of steps. The first step was to identify the concept of strategic leadership, its importance, and then its objectives, and then determine the dimensions discussed for strategic leadership, by reviewing the views of the authors and researchers regarding the details referred to above. In the second step, the two researchers presented their procedural concept of entrepreneurship Strategy as the organization's ability to create new products that are unique and distinguished from competing products. The third step was towards standing on the concept of marketing ambidexterity by reviewing several concepts for a group of writers and researchers, as well as showing the importance of marketing ambidexterity that gain importance because organizations need to adapt Especially with the dynamic increase of the environment, as well as an explanation of its characteristics and conditions, down to a review of the dimensions agreed upon by writers and researchers of marketing ambidexterity.

As for the fourth step, it was represented in finding the truth about the role that strategic leadership can play in enhancing marketing ambidexterity. For this purpose, the two researchers chose the Mosul Alban Laboratoryas a community for their research, and they collected the necessary data for a sample of workers in this community represented by (45) individuals surveyed. By using a special questionnaire form prepared for this research, the fifth step was the statistical treatment of these data within the framework of a set of statistical tests that fit with the data obtained in light of the questionnaire. The necessity of conducting research again in other products or service organizations to draw the attention of departments therein to the importance of strategic leadership as one of the important variables to enhance the organizations' marketing ambidexterity.

Keywords:

Strategic leadership, marketing ambidexterity. 


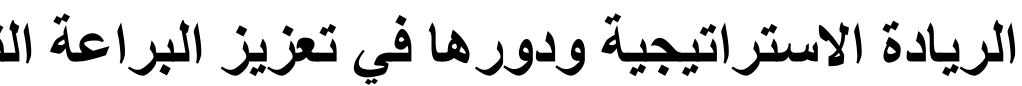

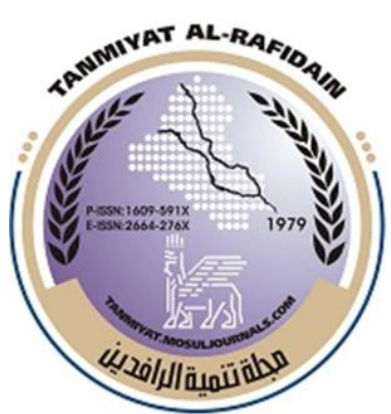

\section{أحمد مرعي حسن 1 ، محمد محمود حامد الملاحسن 2 \\ قسم التسويق، كلية الإدارة والاقتصاد، جامعة الموصل 2\&1}

المؤلف المراسل: أحمد مرعي حسن، قسم التسويق، كلية الإدارة والاقتصاد، جامعة الموصل 94ahmed19@gmail.com

DOI: https://doi.org/ 10.33899/tanra.2021.129904.1085

تاريخ المقالة: الاستلام: 2021/4/8؛ التعديل والتنقيح: 2021/5/1؛ القبول: 2021/5/10؛ النشر: $.2021 / 12 / 1$

المستخلص

سعى الباحثان في جثهم إلى تضمين مجموعة من الخطوات تمثلت الخطوة الاولى نحو الوقوف على مفهوم الريادة الإستراتيجية وبيان اهميتها وثم /هد/فها ومن ثم تحديد الابعاد المبحوثة للريادة الإستراتيجية، من خلال استعراض اراء الكتاب والباحثين بذصوص التفاصيل الدثار اليها اعلاه، وقدم الباحثان في الخطوة الثانية

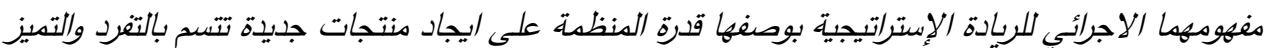
عن المنتجات المنافسة، اما الخطوة الثالثة فكانت نحو الوقوف على مفهوم البراعة التسويقية وذلك من خلال التهرلي استعراض عدد من الدفاهيم لمجموعة من الكتاب والباحثين، وكذلك بيان /هية البراعة التسويقية التي تكتسب أهصيتها لان المنظمات تحتاج إلى التكيف ل سيا مع الزيادة الديناميكية للبيئة، فضلا عن بيان خصائها وشروطها وصولا الى استعراض الابعاد التي اتفق عليها الكتاب والباحثين للبراعة التسويقية. اما الخطوة الرابعة فتمثلت نحو الوقوف على حقيقة الدور الذي يمكن ان تؤديه الريادة الاستراتيجية في تعزيز التئي

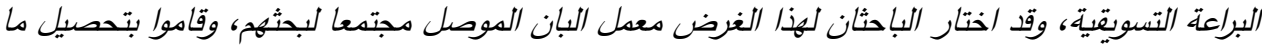
يستلزم من البيانات لعينة من العاملين في هذا المجتمع تمثلت بـ (45) فردا مبحوثا، بواسطة استمارة استبانة خاصة اعدت لأغراض هذا البحث، وتمثلت الخطوة الخامسة بالمعالجة الاحصائية لهذه البيانات في إطار مجموعة من الاختبارات الاحصائية التي تلاءم والبيانات التي استحصلت في ضوء الاستبانة، وتوصل الباحثان الى ايجابية ومعنوية العلاقات بين الدتغيرين، وعلى ضوء ذلك قدم الباحثان جملة من الدقترحات

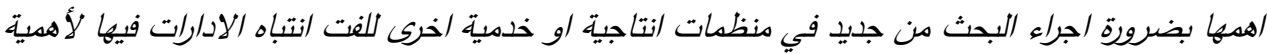
الريادة الاستراتيجية بوصفها احدى المتغيرات المههة لتعزيز البراعة التسويقية للمنظمات.

الكلمات الرئيسة الريادة الإستراتيجية، البراعة التسويقية.
هبلة

\section{تنهية الرافدين}

(TANRA) دولية، مفتوحة الوصول، محكمة.

$$
\text { المجلد (40)، العدد (132)، }
$$
كانون الثاني

(? جامعة الموصل | كلية الإدارة والاقتصاد، الموصل، العراق.

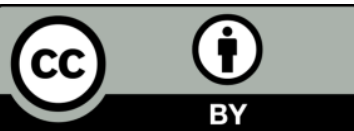

تحتف (TANRA) بحقوق الطبع والنشر للمقالات المنشورة، والتي يتم إصدارها بموجب ترخيص

\lrcorner (Creative Commons Attribution)

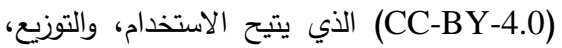
والاستتساخ غير المقيد وتوزيع للمقالة في أي وسيط التيط نقل، بشرط اقتباس العمل الأصلي بشكل صحيح.

الاقتباس: حسن، أحمد مرعي، الملاحسن

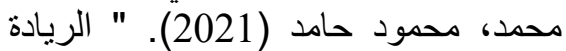
الاستراتيجية ودورها في تعزيز البراعة التانة

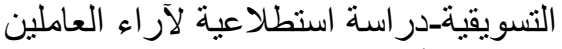
في معمل ألبان الموصل ".

تنمية/الر|فدين،40 (131)، 37-60، https://doi.org/

10.33899/tanra.2021.129904.10 85

P-ISSN: 1609-591X e-ISSN: 2664-276X tanmiyat.mosuljournals.com 
تعد الريادة دفهوم أساسي في أدبيات الإدارة الاستراتيجية هدفها تحقيق مخرجات مرغوب فيها على مستوى المنظمة، إذ تشير أدبيات نظرية المنظمة إلى أن الريادة ظاهرة تبرز على مستوى المنظمة وتهتم بثكل خاص الاصدي

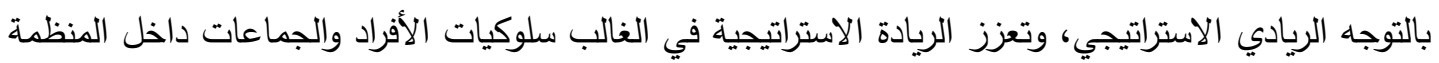

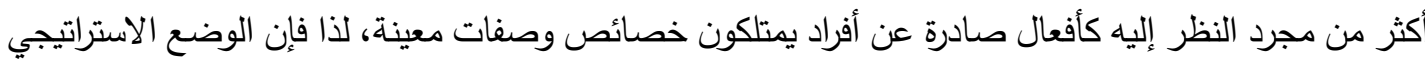
الذي يتخذه مالكو ومديرو المنظمات ذات التوجه الريادي الاستراتيجي يتصفون بمستوى عال من المجازفة والتتبؤ والاتجاه نحو التطوير وتقديم خدمات جديدة ومبتكرة إلى السوق عبر سلسلة من القرارات ذات العلاقة، كما تهدف

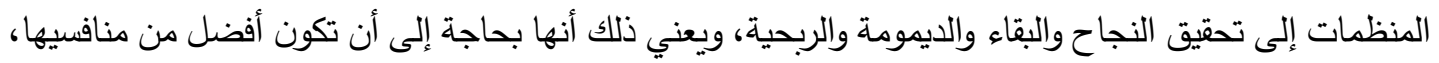

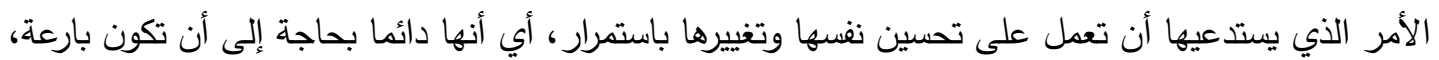

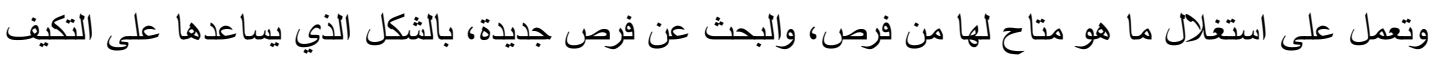

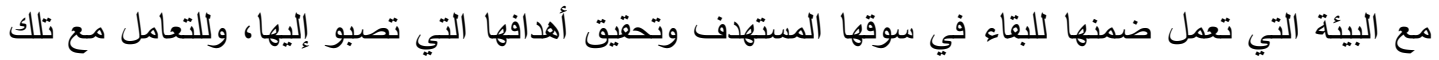
الظروف والتحديات، وجاءت فكرة البراعة التسويقية بوصفها واحدة من بين أهم تلك التوجهات، التي من خلالها تستطيع منظمات الأعمال مواجهة هذه التحديات، والوقوف بشكل قوي تجاهها من أجل بقائها واستمرارها في أداء أعمالها، وتماشيا مع ما تم طرح اعلاه وجد الباحثان امكانية دراسة هذين البعدين (الريادة الإستراتيجية والبراعة التسويقية) وامكانية قياسهما في منظمة انتاجية تعمل ضمن حدود مدينة الموصل، اذ تم اختيار معمل البان الموصل في ضوء دراسة استطلاعية اكد ملاءمته لإنجاز هذا البحث ، والذي ركز على المحاور الاتية :

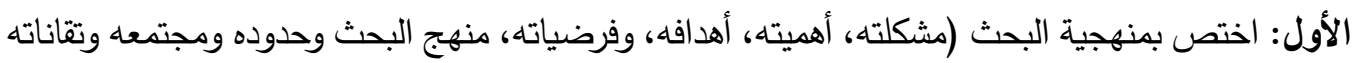
وعينته)، اما الثاني: اشتمل على الإطار النظري، الذي أسس لمتغيري البحث (الريادة الاستراتيجية، البراعة

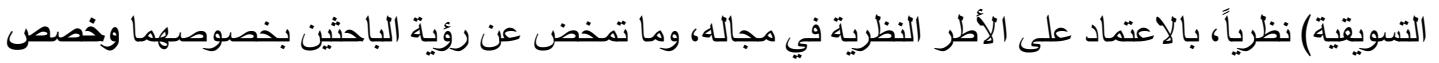

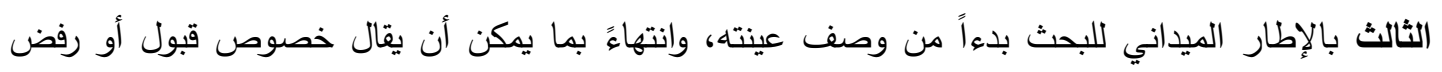

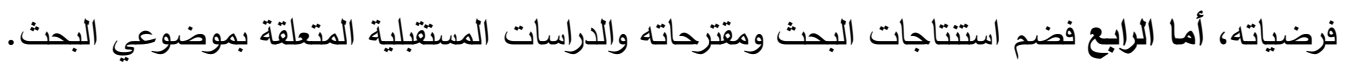
المحور الأول/ منهجية البحث أولاً: مشكلة البحث

تعد الريادة الإستراتيجية اداة النجاة للمنظمات في وقتنا الحالي، ذلك لأنها تبحث عن الطرائق الجديدة التي

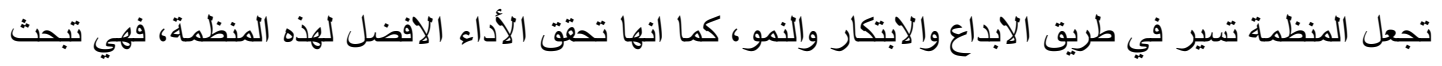

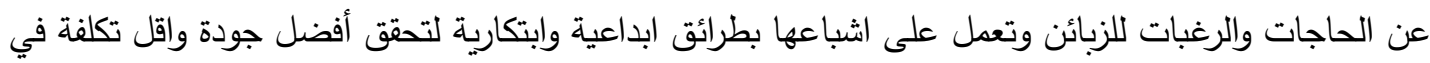

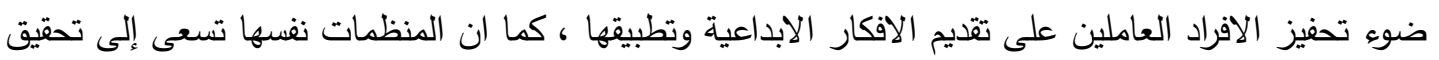
التميز وتحقيق التقوق على المنظمات الاخرى، لذا نجدها انها لا تتردد في تبني الاساليب الجديدة في المجال

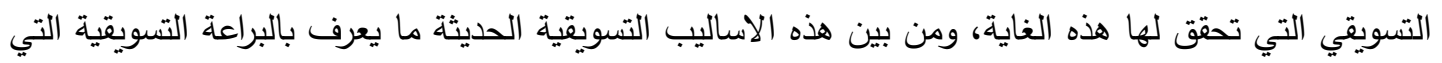
تسعى لاستكثاف الفرص الواعدة واستثمارها بطريقة تتسجم مع ما يتوفر للمنظمة من موارد والقدرة على التغيير 
في انثطتها التسويقية وذلك لتحقيق التفوق التنافسي على المنظمات الاخرى، من هنا تظهر اشكالية الريادة الإستراتيجية بوصفها احدى الادوات المهمة لتحقيق وتعزيز البراعة التسويقية للمنظمات، والتي انبثق عنها

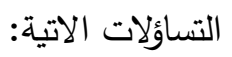

• التساؤل الرئيس الاول: هل هنالك تتحس للبراعة التسويقية تجاه الريادة الاستراتيجية في المنظمة المبحوثة. • التساؤل الرئيس الثاني. هل هناك علاقة ارتباط بين الريادة الاستراتيجية والبراعة التسويقية.

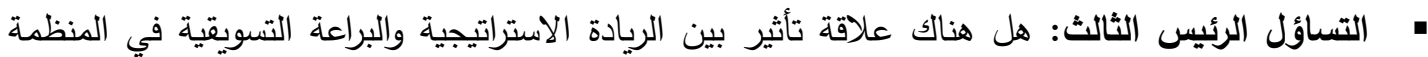
المبحوثة. ثانياً: اهمية البحث واهدافه: تبرز أهمية هذا البحث من أهية أهدافه في سعيها نحو توفير الإجابات عن

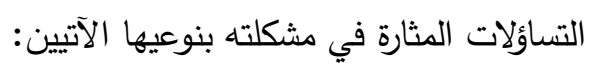
النظرية: التي قد تتجلى بوصفهما أن توفر بمجملهما إطاراً نظريًا يعكس ماهية التفاصيل المتعلقة بكل متغير من المتغيرين المبحوثين، وبما يفيد كمرجعية للباحثين بخصوصهما.

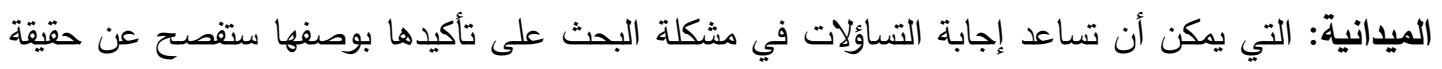
الدور الذي تؤديه الريادة الإستراتيجية في تعزيز البراعة التسويقية في المنظمة المبحوثة.

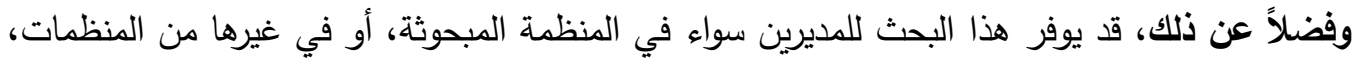

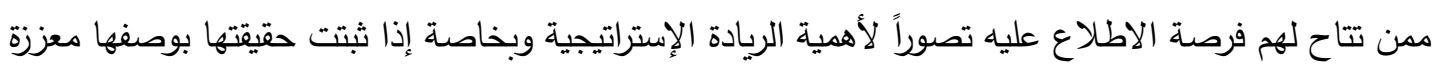
للبراعة التسويقية.

ثالثاً: مخطط البحث الافتراضي وفرضياته: تتحدد فرضيات هذا البحث بالفرضيات الرئيسة والفرعية الآتية:

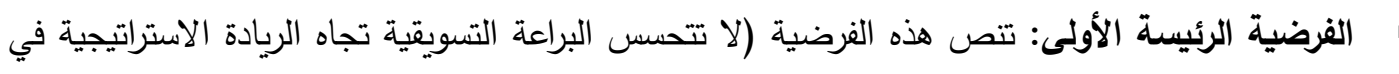
المنظمة المبحوثة). • الفرضية الرئيسة الثانية: تتص هذه الفرضية (لا توجد علاقة ارتباط بين الريادة الاستراتيجية والبراعة

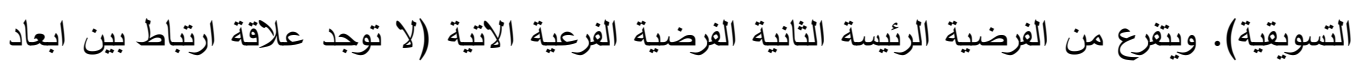
متغير الريادة الاستراتيجية وابعاد متغير البراعة التسويقية). الفرضية الرئيسة الثالثة: والتي تتص (لا توجد علاقة تأثير بين الريادة الاستراتيجية والبراعة التسويقية في

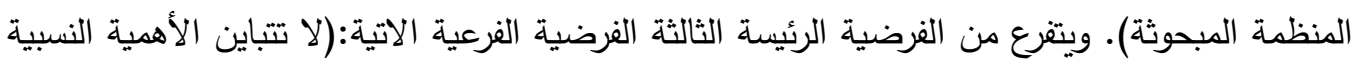
لأبعاد متغير الريادة الاستراتيجية على متغير البراعة التسويقية في المنظمة المبحوثة).

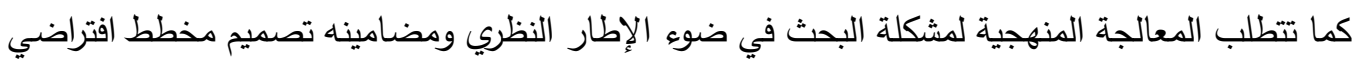
متمثلاً بالثكل (1) الذي يشير إلى العلاقة المنطقية بين متغيرات البحث، ويمكن توضيح مخطط البحث بالثكل 
الثكل (1): مخطط البحث الافتراضي

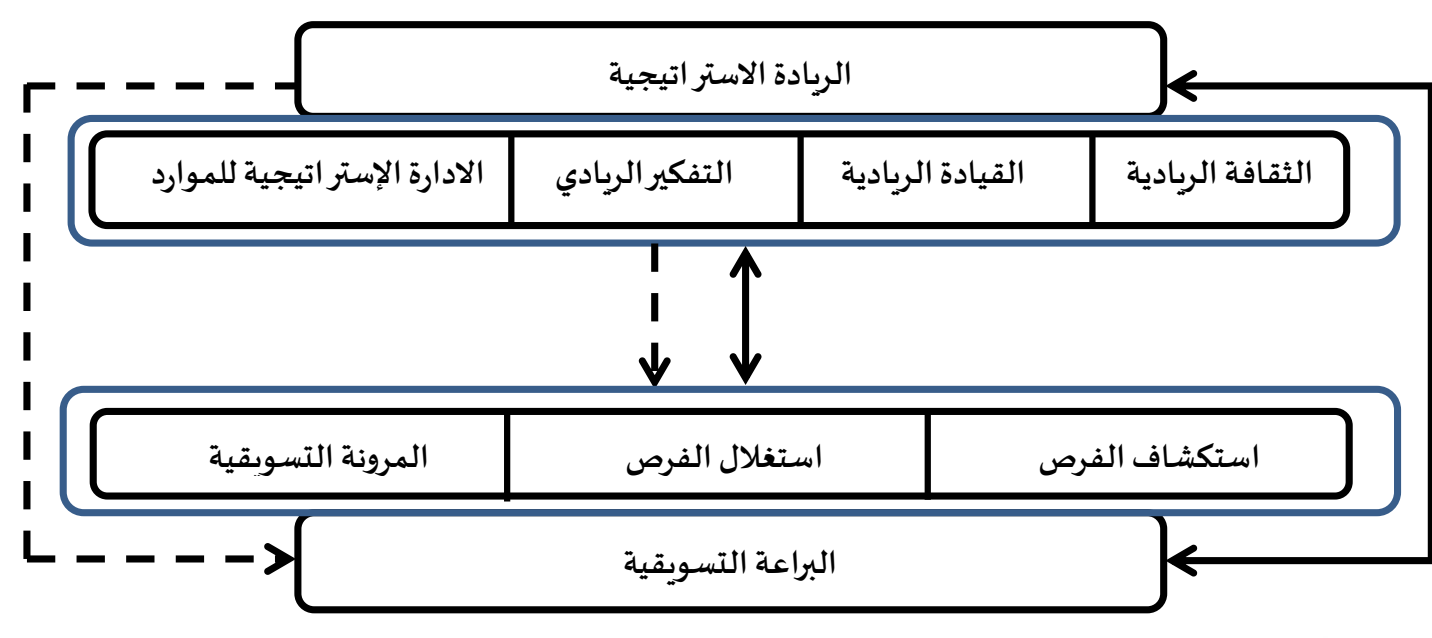

علاقة الارتباط

علاقة التأثير علاعه

المصدر: من إعداد الباحثان

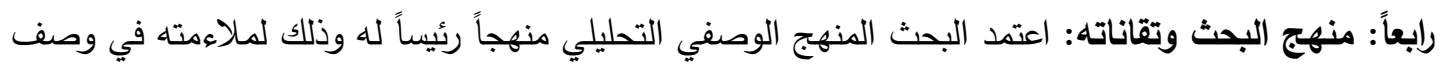
أبعاد البحث، وانطلاقاً من ذلك اعتمد على تقانات هذا المنهج في الحصول على البيانات المناسبة لإنجاز البحث، من خلال الكتب والرسائل والاطاريح والبحوث لبعض الكتاب والباحثين وكذلك من خلاد الثبكة

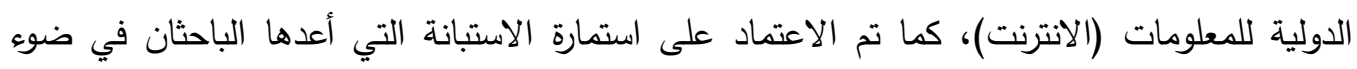

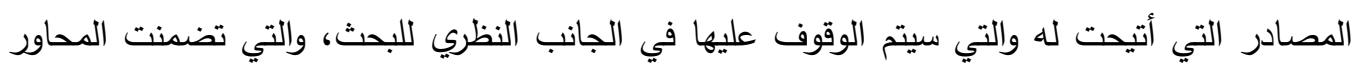
الآتية:

الأول: أختص بالحصول على البيانات التي تصف خصائص المستبينة آراؤهم من أفراد العينة العشوائية للبحث والذين سيتم وصفهم اعتماداً عليها لاحقاً. الثاني : أختص بالحصول على البيانات المناسبة لإنجاز البحث، وتضمن (41) مؤشراً، تغطي متغيرات البحث.

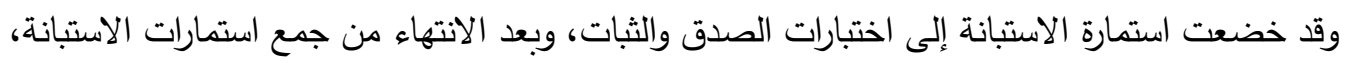

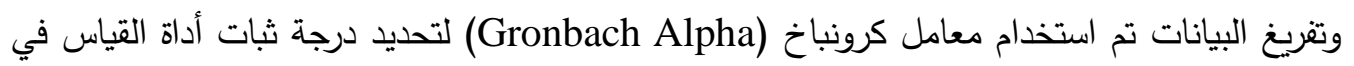
هذا البحث، وتبين أَنَّ نسبة التطابق في إجابات أفراد عينة البحث بلغت على البعلى المستوى الإجمالي (82.5

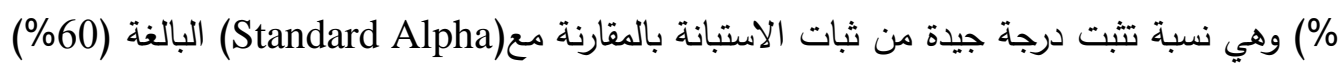
الخاصة بالدراسات الإنسانية (Afifi, Clark, 1989,390)، كما وتجدر الإشارة إلى أن الاستمارة المشار إليها تم توزيعها على عينة عشوائية لعدد من الافراد العاملين في معمل البان الموصل البالغ عددهم (45) فرداً، وسيقف الباحثان على أوصاف هذه العينة في مستهل الإطار الميداني لبحثهما لاحقاً . 
وأخيراً فيما يتعلق بتقانات التحليل: فقد تم اعتماد برنامج النظام الجاهز (SPSS-24) والذي بواسطته تم

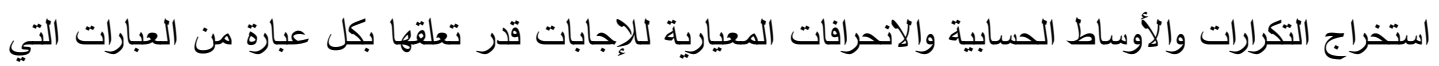
وردت بالاستبانة، وكذلك بعض الاختبارات التي اختارها الباحثان بوصفها من الاختبارات المناسبة في دراسة العلاقات بين متغيرات البحث المختلفة. خامساً. حدود البحث 1. الحدود المكانية: تمثلت الحدود المكانية للبحث بالأفراد عينة البحث والذين استطاع الباحثان التوصل إليهم وتوزيع استمارات الاستبانة عليهم والذين يتواجدون ضمن الحدود الجغرافية لمدينة الموصل.

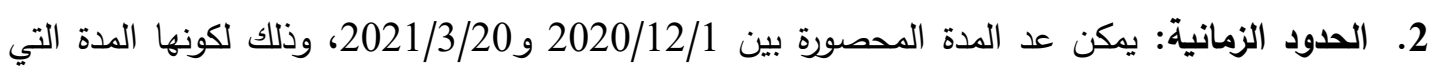
أنجز فيها هذا البحث بدءاً من الشروع بمهام تحصيل البيانات من المجتمع المبحوث وانتهاء بإنجاز البحث وطباعته. المحور الثاني/ الإطار النظري

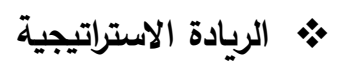
أولاً: مفهوم الريادة الاستراتيجية ذكر (Ibrahim\&Jawad,2018,249) بأن الريادة الإستراتيجية مصطلح

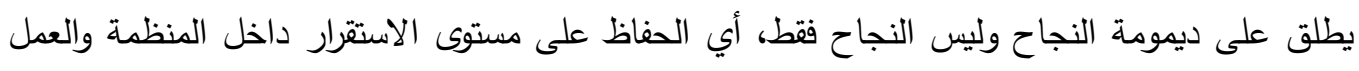
على تطوير وتوسيع ذلك النجاح والتفوق على المنافسين، وان تبني سلوك إداري بمغامرة محسوبة من أجل

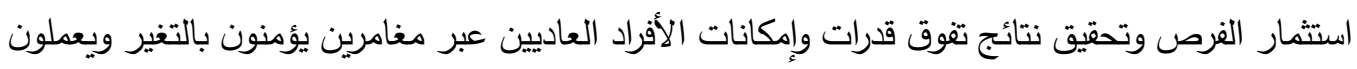
على تحقيقه أي انها عملية تأخذ على عاتقها مخاطر اقتصادية مرتبطة بعدد من المفاهيم. فهي استثمار

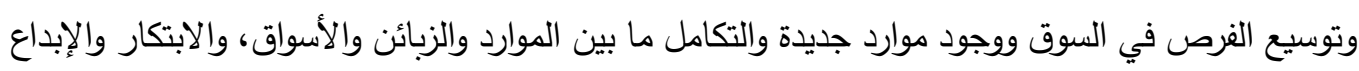

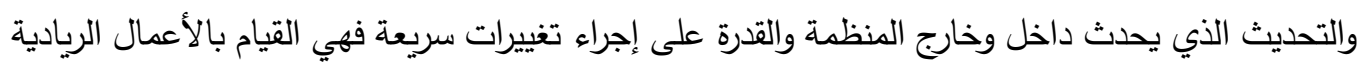

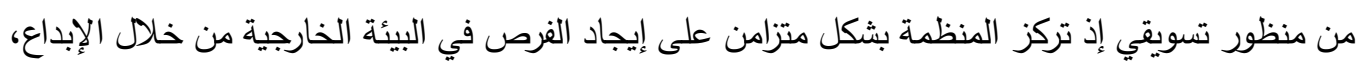

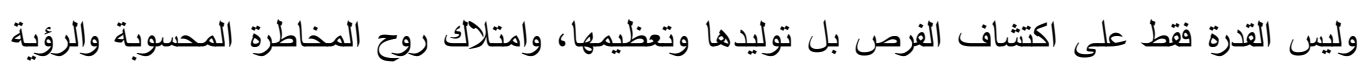

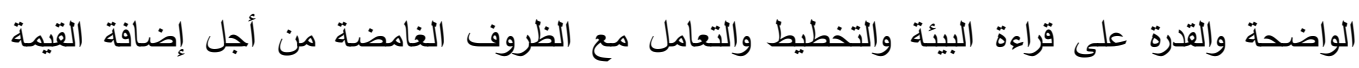

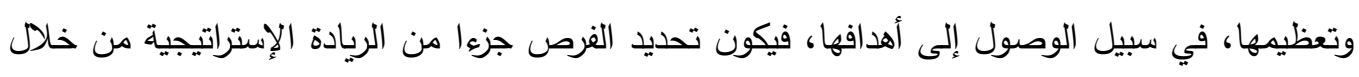

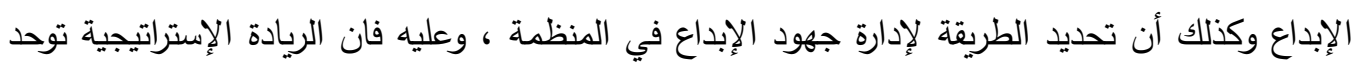

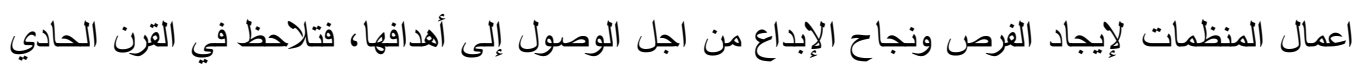

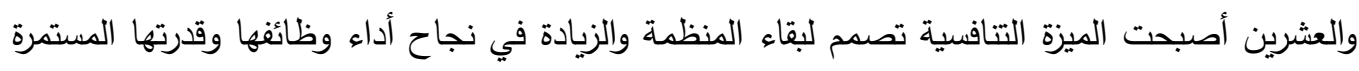
لإيجاد الفرص الجديدة للإبداع (AL-Hakim \& Ali, 2017, 55). ومنهم من أكد بأن الريادة الاستراتيجية ينتج منها منظورا استراتيجيا للأنشطة الريادية وهي ايضا نشاط استراتيجي من خلال عقلية او تفكير ريادي الإدي (2013,31 etal, Chang,)

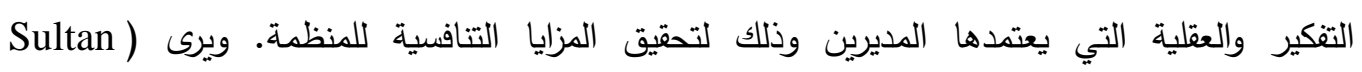


Al-Hamad \& Ali, ( 168 \&Hajji,2016, 257, 2020) فقد وصفوها بأنها غاية من الغايات التي تعمل على تثجيع طموح المنظمة وتحفيز سلوك طايه البحث عن الفرص لدى العاملين في المنظمة من خلال مجموعة من الأنشطة الداعمة لتحقيق الابتكار

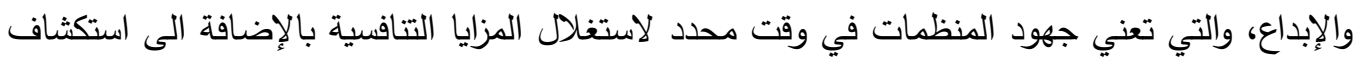

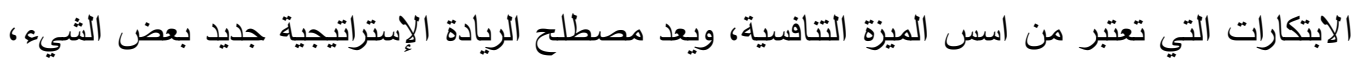

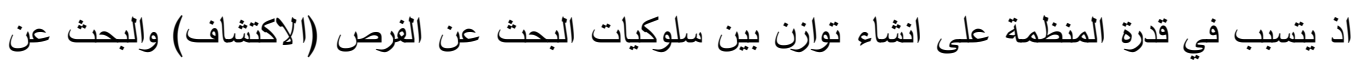
الميزة ، وهي أحدى مجالات المنظمة التي تتضمن الريادة، إذ تركز على المستتبل اضافة الى الاعمال

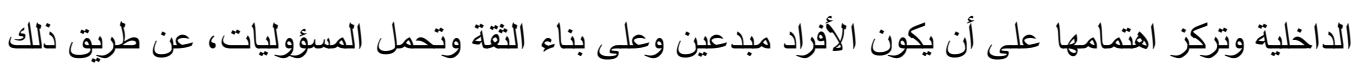

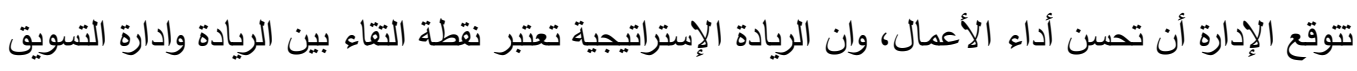

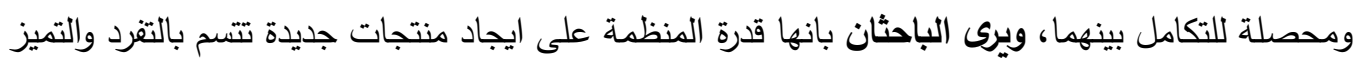

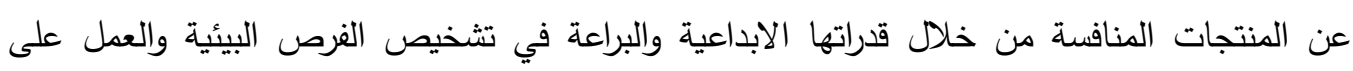
استغلالها والاستعداد للتعامل مع التهديدات التي قد ترافقها من خلال الخبرات المكتسبة والتعلم. ثانياً: اهمية الريادة الإستراتيجية: إن طموح اي منظمة هو الوصول الى الريادية في مجال اعمالها، وعندما

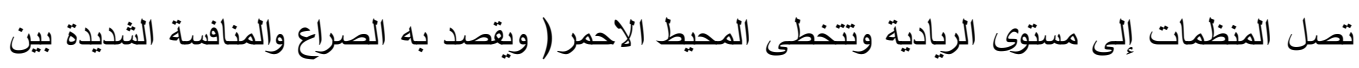

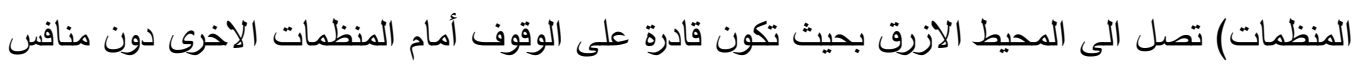
لها وذلك لأنها فريدة بمنتجاتها المبتكرة في السوق، لذا فهي غاية مهمة للمنظمات لتلبية طموحها في

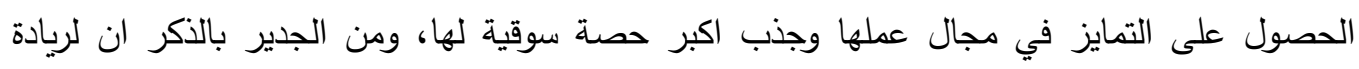

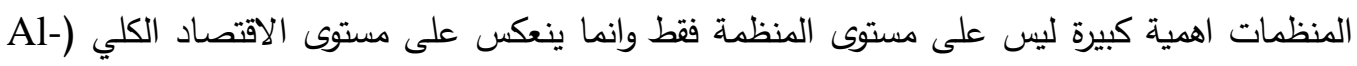

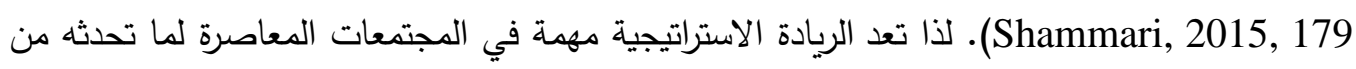

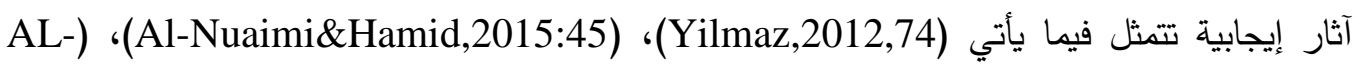
،(Amer \& Sukkar, 2020,35)، (Hakim \& Ali, 2017, 57 1. الريادة الاستراتيجية هي تكامل الريادة والادارة الاستراتيجية، اذ تبرز اهمية هذا التكامل في تكوين الاستراتيجية

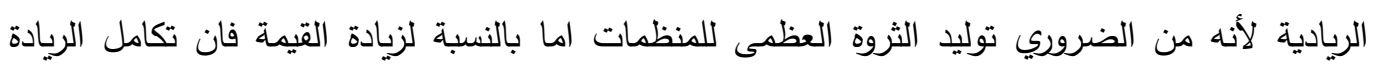
والاستراتيجية سيقودنا الى تحقيق النجاح. 2. تدعو الادارة الاستراتيجية الى تأسيس واستغلال الميزة التنافسية ضمن سياق التئية بيئي معين في حين تعزز

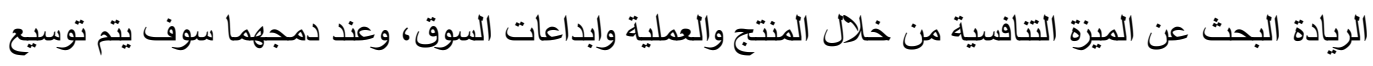

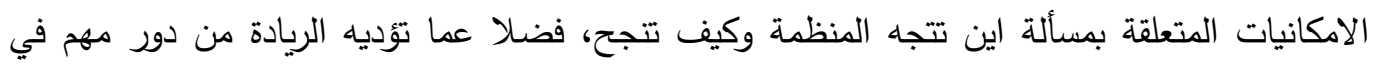
استراتيجية المنظمة. 3. تخفيض درجة المخاطر بفضل وجود تصورات للتطورات التقنية الجديدة وتحفيز المواهب الداخلية على البقاء

$$
\text { في المنظمات والاستمرار في العمل فيها. }
$$


4. إن التوجه الريادي يساعد المنظمة على التتبؤ بالمستقبل ونتيجة لذلك يجب أن تتبنى المنظمة المرونة

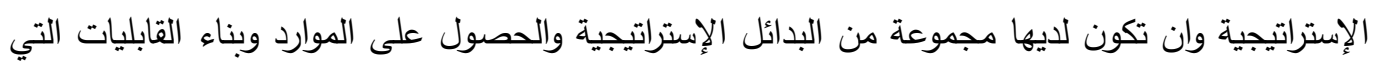

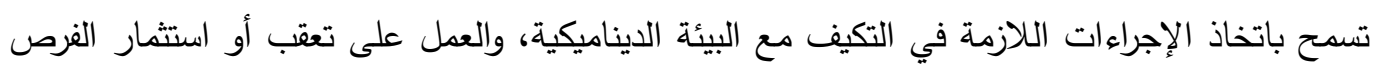

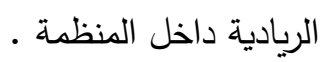

ويرى الباحثان ان اهية الريادة الاستراتيجية تكمن في امكانية حصول المنظمة على حصة سوقية اعلى

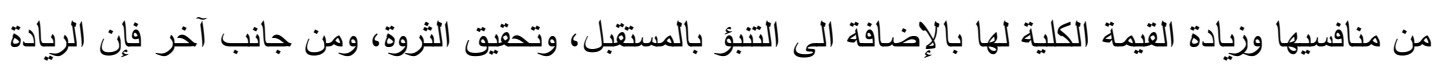
تؤدي الى تخفيض درجة الخطورة المحدقة بالمنظمة وذلك من خلال قيام المنظمة باستخدام التقنيات الحديثة لأغراض التتبؤ والبحث عن الفرص الواعدة واستغلالها الاستغلال الامثل.

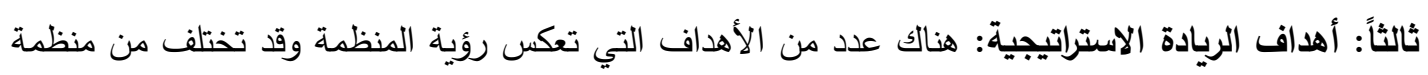

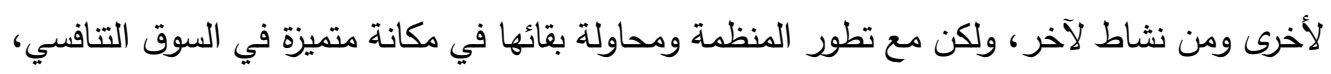

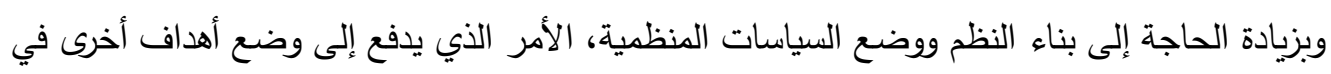

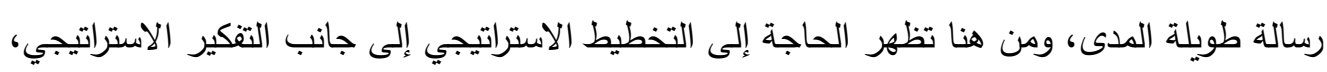

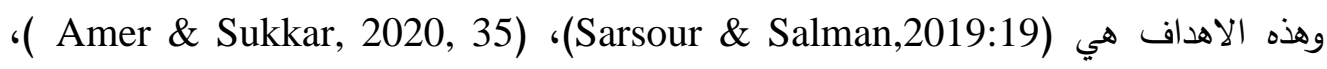

:(Zenati, 2020, 148)

1. تحديد أولويات طويلة الأجل للمنظمة في ضوء الرسالة الحالية والتغيرات والتحولات في الظروف البيئية

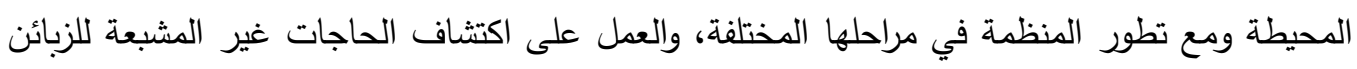
والأسواق غير المخدومة واستهدافها لتحقيق الميزة التتافسية، إضافة الى تحقيق أرباح عالية من الاستثمارات الجديدة، والعمل على تطوير منتجات جديدة تؤدي الى أضافة قيمة جديدة للمنظمة.

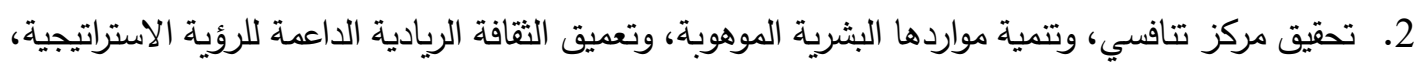
وتعزيز الأنشطة الداعمة للتجديد والابتكار، وتحمل المخاطر من أجل البقاء والتطوير في ظل التغيرات الديناميكية المتسارعة. 3. تحسين الوضع الحالي والمستقبلي للمنظمة، والتوظيف الذاتي حيث توفر للرياديين مزيد من فرص العمل

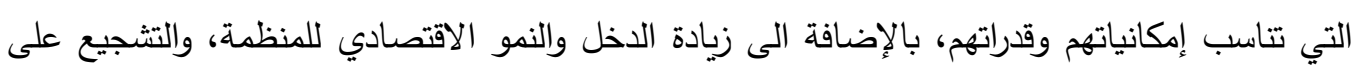
تقديم خدمات مميزة وذات جودة، ومن جانب آخر يتم التأكيد على استخدام التكنولوجيا الحديثة في تقديم

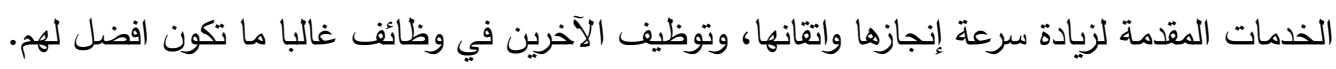

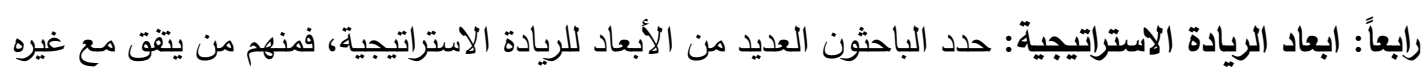

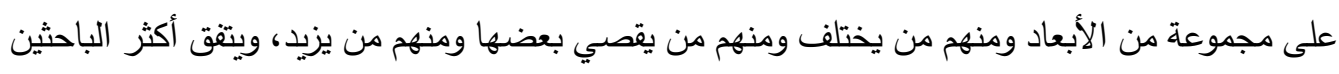

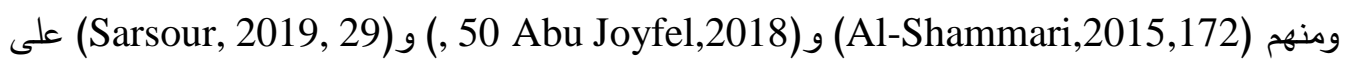
أن الأبعاد الرئيسية للريادة الاستراتيجية هي: 
1. الثقافة الريادية: هي عبارة عن القيم الاجتماعية المشتركة ودرجة الاعتقاد بها، التي تصيغ هيكل إجراءات المنظمة لأعضائها من أجل وضع المعايير السلوكية (أي طريقة إكمال العمل في المنظمة) فالتقافة الريادية

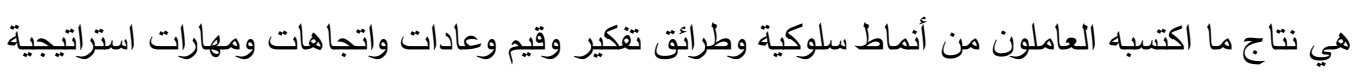
ريادية قبل انضمامهم للمنظمة التي يعملون فيها (Amer \& Sukkar, 2020, 38). وعرفها (

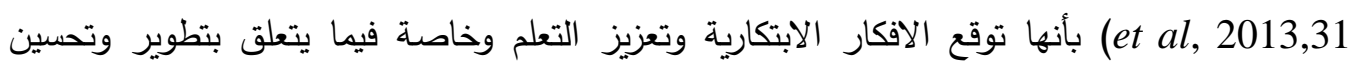

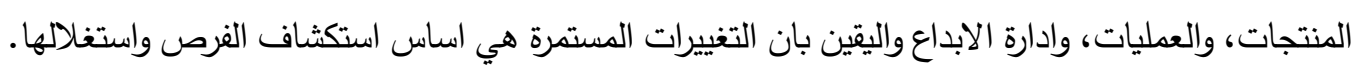
وأكد (AL-Hakim \& Ali, 2017, 64) بأن الثقافة الريادية الفاعلة تتميز بتسهيل جهود الكنظمة لإدارة الموارد إستراتيجيا، إذ تتضمن: الأفكار الجديدة، تثجيع المخاطرة أو تحمل الفشل، ترويج التعلم، تبني

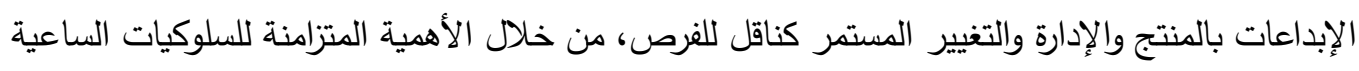
وراء الفرصة والميزة، ولهذا السبب تتبنى الثقافة الريادية وتدعم البحث المستمر عن الفرص الريادية المككن

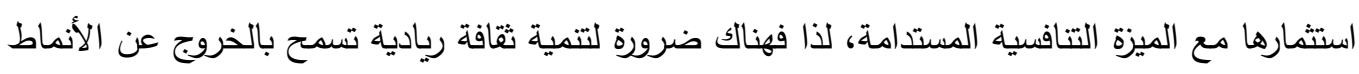

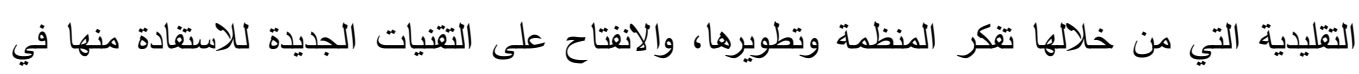

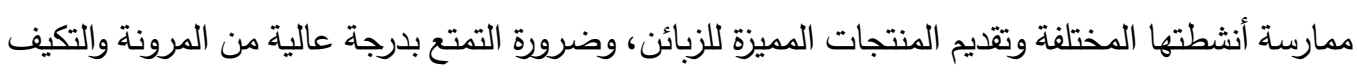
التغيرات التي قد تحصل في البيئة الخارجية، والاستعداد لتحمل بعض حالات الفشل.

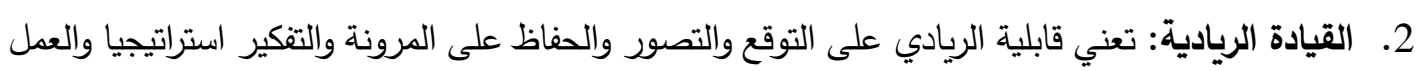

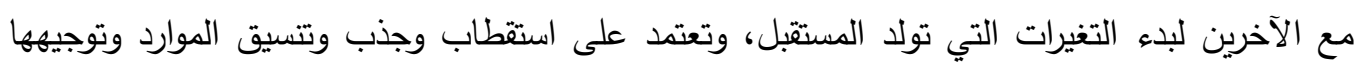

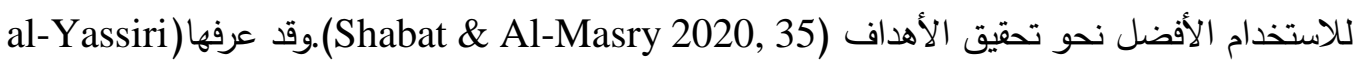

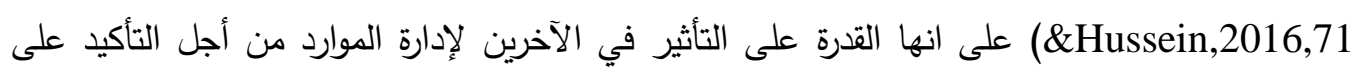
البحث عن الفرصة وسلوكيات البحث عن الميزة التنافسية.

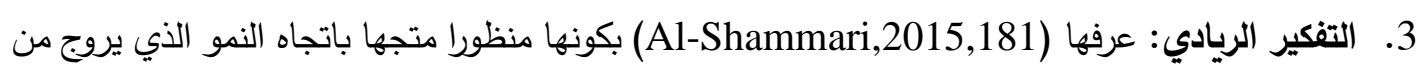

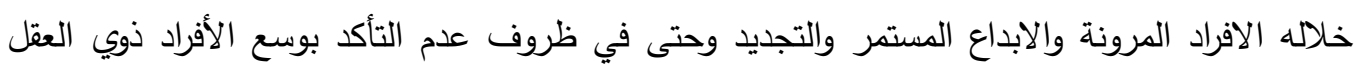

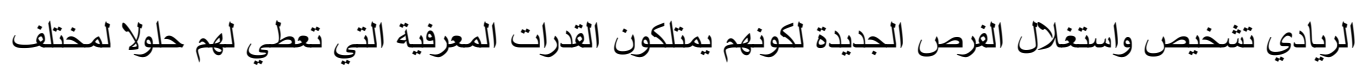
الحالات الغامضة ويتصف بالإدراك للقرص الريادية والتأهب والبحث عن الحقيقة.

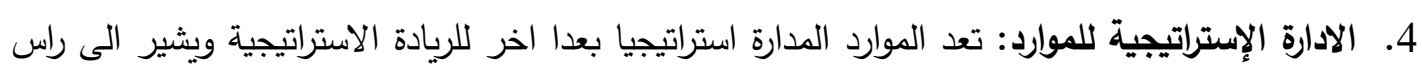

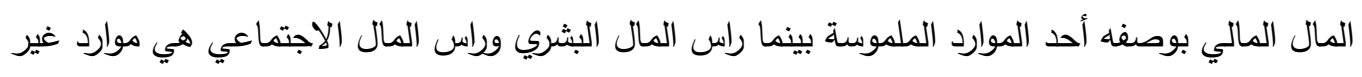
ملموسة وتعد اساس الأداء التفاضلي للمنظمة من حيث توليد الثروة، اذ ان الموارد المدارة استراتيجيا يسهل نشرها مع تزامن استخدام سلوكيات البحث عن الفرصة والميزة، فضلا عن المنظمات التي تتبنى محفظة التهاه الموارد لتشكيل القدرات ورفع تدفق هذه القيمات من اساسها المالي والبشري والاجتماعي الى سلوكيات

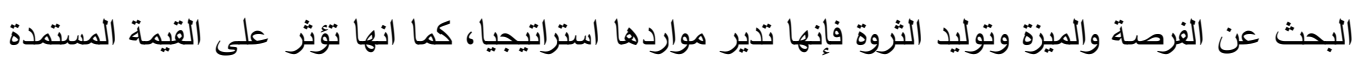


Al-Nuaimi ( من الموارد الملموسة وغير الملموسة التي تستخدمها المنظمة لتطوير وتتفيذ استراتيجياتها .(\& Hamid, 2015, 46

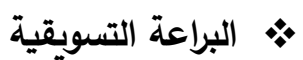
أولاً: مفهوم البراعة التسويقية: نتيجة للتطورات الحاصلة في المجالات كافة والبحث المستدام من قبل المنظمات

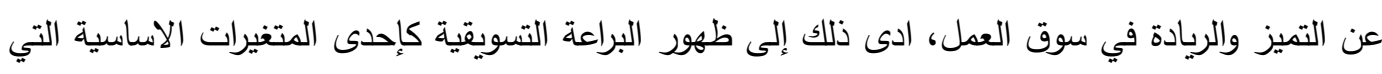

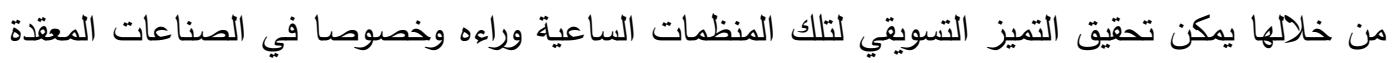
(Duan \& Zhang, 2010,3) الاستغلال والاستكثاف والمرونة التسويقية في وقت واحد بطرق تؤدي إلى تعزيز الفاعلية في المنظمات، فهي قادرة على تحقيق التوازن بين استغلال القدرات الحالية، واستثمارها وتحقيق المرونة التسويقية لجني

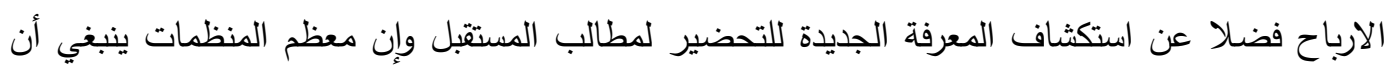
تكون بارعة من خلال استغلال المعرفة (Ahmed\& Ismail, 2019, 9). والجدول (1) يبين البراعة

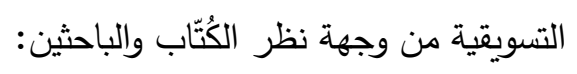
الجدول (1): البراعة التسويقية من وجهة نظر الكُتّاب والباحثين

\begin{tabular}{|c|c|c|}
\hline التعريف & الكتاب والسنة & ت \\
\hline قائمة على البراعة التسويقية تساعد في تجريب بدائل جديدة تساهم في تحقيق إضافة تسويقية آنية & $\begin{array}{l}\mathrm{Xu} \quad \text { et } \\
2016,118\end{array}$ & 1 \\
\hline 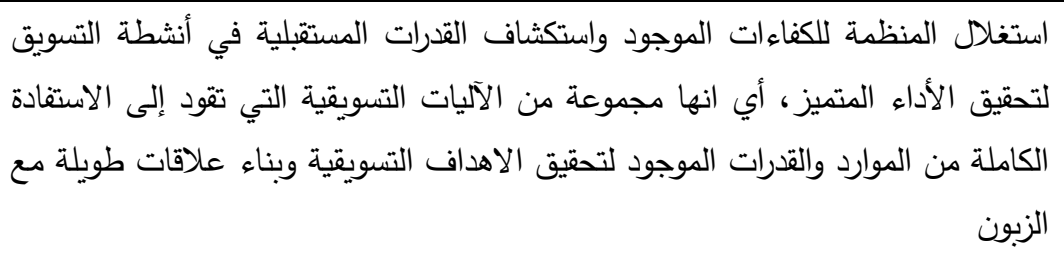 & $\begin{array}{l}\text { AL-Mousawi, } \\
2018,449\end{array}$ & 2 \\
\hline 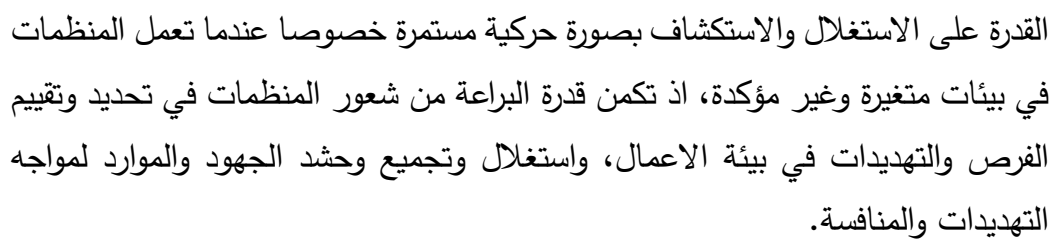 & $\begin{array}{l}\text { Ahmed } \quad \& \\
\text { Ismail, } 2019, \\
257\end{array}$ & 3 \\
\hline هي قدرة المنظمات على تحقيق النجاح من خلال القادة المؤهلين ويتم من خلال استغلال & $\begin{array}{l}\text { Al-Awda, } \\
2020,559\end{array}$ & 4 \\
\hline
\end{tabular}

المصدر: من اعداد الباحثان بالاعتماد على المصادر اعلاه. ثانياً: اهمية البراعة التسويقية: تبرز أهميتها من خلال أثرها في عملية التكيف مع الظروف الإدان البيائية المتغيرة والحصول على ميزة تتافسية مستدامة ومدى اعتماد هذه التغيرات إلى حد كبير على استغلال الموارد 
الحالية واستكثاف الفرص الجديدة من أجل الابتكار، وتكتسب البراعة التسويقية أهمية لان المنظمات

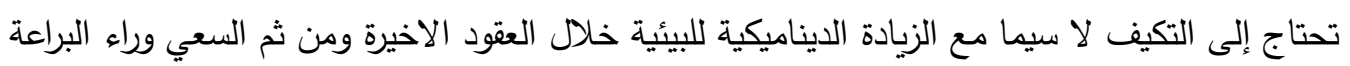

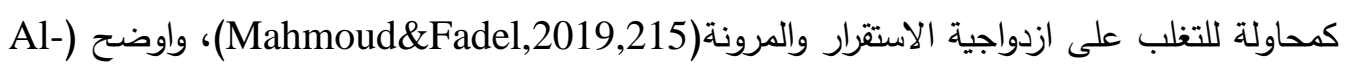

(Ani\&Hussein,2018,279

ان البراعة التسويقية ترتبط بتحقيق النجاح على الأمد الطويل كونها تبحث في تحقيق التوازن بين الاستكثاف والاستغلال بثكل متزامن وبما يتلاءم مع البيئة التسويقية المحيطة بالمنظمة، وغالبا ما ترتبط البراعة التسويقية المئية

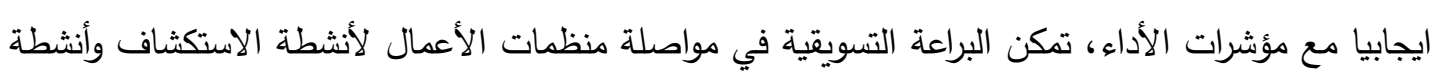

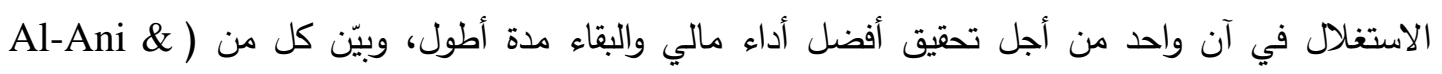

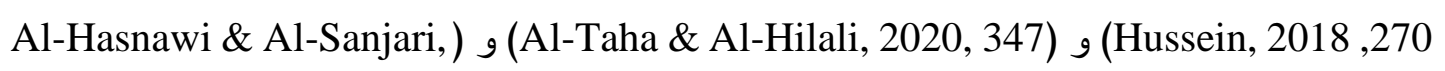
2020, 43 1. تحقيق النجاح للمنظمات على المدى البعيد من خلال التوازن بين استكثاف الفرص واستغلآلالها وانعكاس ذلك على مؤشرات الاداء بشكل ايجابي. 2. تمنح منظمات الاعمال مجموعة من الخيارات لتوليد النتائج المهمة حول ادارة التتاقضات والتوترات في التعامل الحالي والمستقبلي لتحقيق الامثلية والابداع. 3. تمكن منظمات الاعمال في تتويع مهاراتها في الجمع بين الفرص الحالية والرؤى المستقبلية في ظل الظروف الإلف التي تتصف بدرجة عالية من عدم التأكد البيئي. 4. تساعد المنظمة على تطوير قدراتها للتحول نحو الفرص الجديدة وكيفية ايجادها في المدى القصير بهدف تلفئف تحقيق القيمة التي تمثل شرط النجاح الاساسي للمنظمات. 5. تبرز اهميتها كوسيلة انثطة ومسارات جديدة تساعد في التغيير والتميز التتظيمي لمواءمة التطورات البيئية في ظل المنافسة السوقية. 6. مواجهة التحديات البيئية التي تحتم على المنظمة البحث عن السبل الكفيلة بتحقيق النجاح والاستمرار في البيئة.

ثالثا: خصائص وشروط البراعة التسويقية: أشار (Bodwllm \&Chermack, 2010,26) أن للبراعة

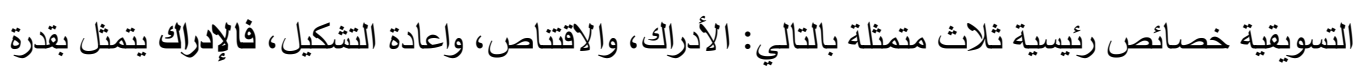
العاملين في المنظمة على تحديد الفرص والتهديدات المستتدة على تحقيق توازن بين شقي الرقابة (مركزية

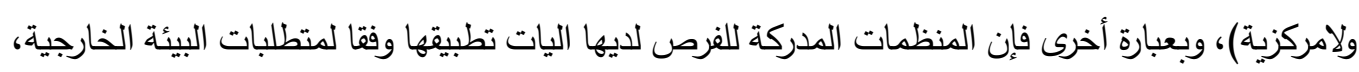
أما الاقتناص فهو قدرة المنظمات على الحصول فرص ولئارة جديدة، وهذا يتطلب توافقا بين الإدارة العليا حول

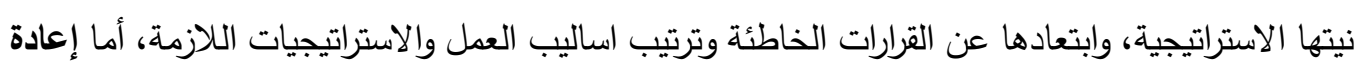
التثكيل فتتمثل بقدرة المنظمات على اعادة محاذاة الأصول مع الهياكل وتثكيلها حسب التبت التطورات التهات السوقية. فالقدرة على إعادة تثكيل الموارد، والأصول، والهياكل، ووظيفة المورد البشري، تعد ميزة إستراتيجية لإعادة الإدل 
تثكيل تتظيمي مؤكدة، فإعادة التثكيل تتطلب موارد كفؤة وفاعلة (Alwan, etal., 2019, 212).وبين (Abbas \& Al-Mahasna, 2017, 27)

$$
\text { ان تأخذها بنظر الاعتبار وهي: }
$$

1. ضرورة استغلال المنظمة والاستفادة من كل مواردها للحفاظ على العمليات اليومية بالتركيز على الانشطة الحالية في المجالات القائمة، إضافة إلى الاستفادة من كل ما يستثر من موارد للبحث والتتقيب عن أنشطة

$$
\text { جديدة في مجالات غير قائمة. }
$$

2. ضرورة تحقيق التوازن النسبي بين أنشطة الاستكثاف والاستغلال والذي يتحدد اعتمادا على الموارد المتاحة للمنظمة مع الاخذ بنظر الاعتبار التطورات والتغيرات البيئية. 3. تحقيق التوزان بين أنثطة الاستكثاف والاستغلال الذي يتطلب العديد من الوسائل يتم اعتمادها في ظل

سياقات مثل التعلم التنظيمي والابتكار والتكيف والسيادة الاستراتيجية. 4. على المنظمة ان توضح السبب في تتابع الوحدات؛ لكي يتم الاستغلال الامثل للفرص وكذلك القيام بالبحث

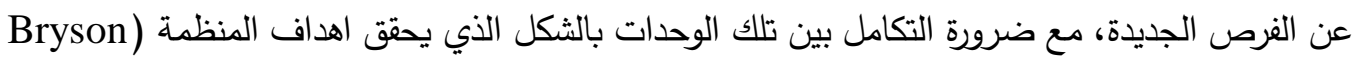
.(et al,2008, 228 رابعاً: ابعاد البراعة التسويقية: تؤكد النظرية التسويقية الحديثة إن مفتاح النجاح لأي منظمة يرتبط بدرجة اكبر

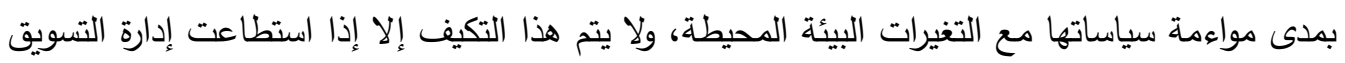

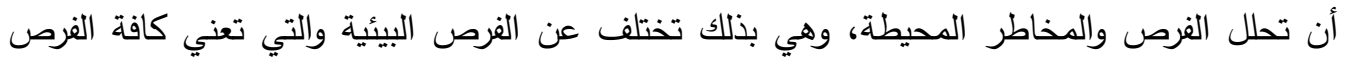
المتاحة في البيئة، لذا يمكن ان تكون الفرص التسويقية إحدى أهم الفرص البيئية والتي يعتمد تحديدها

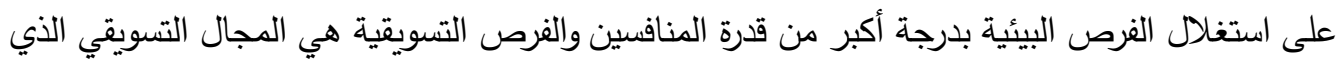

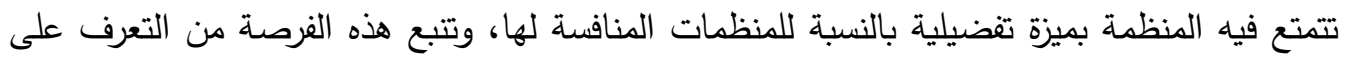
الفرص المختلفة المتاحة في البيئة التي تعمل فيها المنظمة، وغالبا ما تأتي الفرصة التسويقية نتيجة

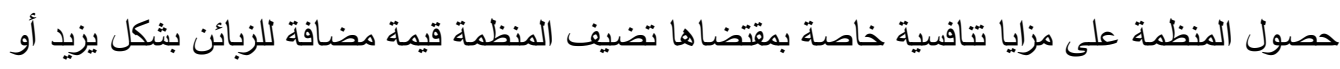
يختلف عن ما يقدمه المنافسون في السوق، وبما يمكن المنظمة من تقديم مجموعة من المنافع تزيد عن هؤلاء المنافسين ، أو تقديم نفس المنافع بمزايا إضافية كان تكون بسعر اقل فئا بلئلا.

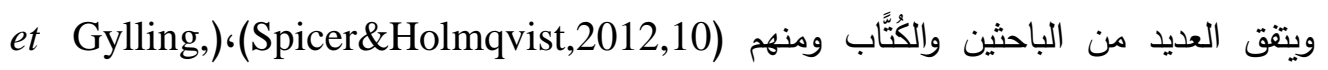
al,2012,1284 )، (Shirokova,etal,2013:333) أن ابعاد البراعة التسويقية هي:

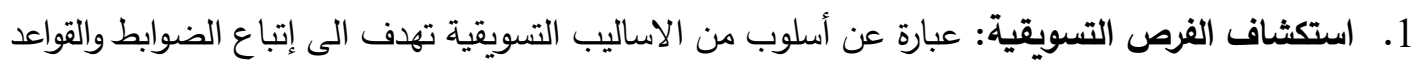

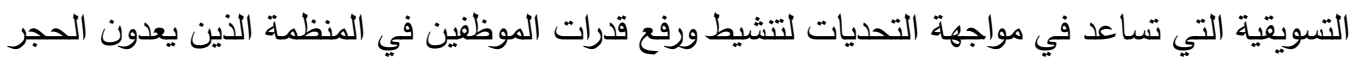
الأساس للقابليات والقدرات الضرورية لتتفيذ الخطط الاستراتيجية التي يمكن من خلالها البحث عن الموارد الثحيحة والفرص التي تتوفر في الزمان والمكان المناسبين، وذلك لتطوير وتحسين قدرة المنظمة على بلى 
تحقيق البقاء في السوق التتافسية وتثجيع الموظفين على استكثاف طرق وممارسات جديدة ومبتكرة للعمل في الابتكار والتطوير المستمر لتحقيق الأهداف التسويقية. 2. استغلال الفرص التسويقية: وهي عبارة عن إستراتيجية تسويقية تمثل قاعدة اساسية لإنجاح التوجهات الاستراتيجية للمنظمة نحو المنافسة في السوق الخارجي؛ وذلك لتعزيز الدوافع اللازمة لتحقيق زيادة المبيعات والنمو ومعالجة بعض القيود والتحديات وتعزيز القدرات التسويقية والتقليل من تأثير البدائل التسويقية على ودئي

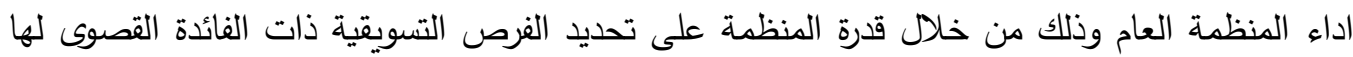
والتوجه نحو استكثاف تلك الفرص بطريقة تفوق قدرة المنافسين وتؤدي الى تحقيق ميزة تتافسية ذات قيمة عالية تحقق جميع الأهداف المرجوة للمنظمة. 3. المرونة التسويقية: تعبر عن توجه الإدارة العليا للتكيف والاستجابة المستمرة مع التغيرات التي تحدث في طلبات وأذواق الزبائن لغرض اتخاذ قرارات تؤدي الى تحقيق مجموعة من الأهداف التسويقية والإستراتيجية

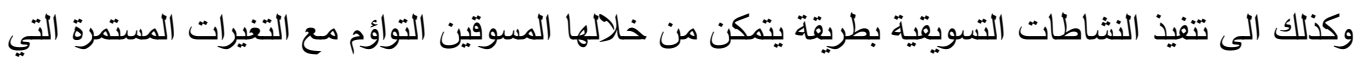
تحدث في البيئة الخارجية لتحقيق متطلبات ورغبات وحاجات الزبائن الحاليين والمستقبليين. المحور الثالث: وصف متغيرات البحث وتثخيصها واختبار فرضياته

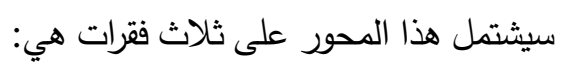
أولا. وصف الأفراد المبحوثين : يمكن القول اعتمادا على معطيات الجدول(2) بنضوج الأفراد المبحوثين، وذلك

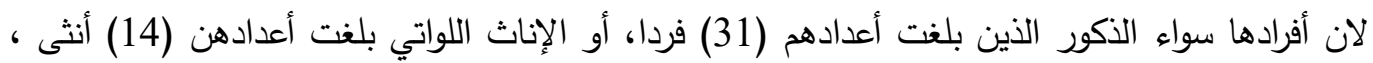
يعدون من حيث العمر في قمة عطائهم ، وذلك لان معظمهم واقع ضمن الفئات العمرية المتوسطة والمحصورة بين (31-50) ، مع بعض الاستثناءات التي وصلت على مستوى من هم أعلى من هذه الأعمار ما نسبته

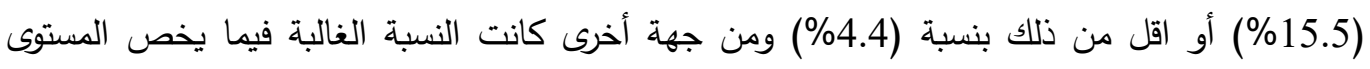

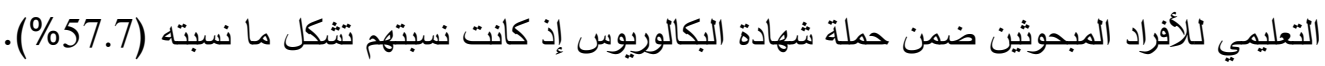
جدول (2): وصف أفراد العينة المبحوثة

\begin{tabular}{|c|c|c|c|c|c|c|c|}
\hline \multicolumn{8}{|c|}{ الجنس } \\
\hline \multicolumn{4}{|c|}{ إناث } & \multicolumn{4}{|c|}{ ذكور } \\
\hline \multicolumn{2}{|c|}{$\%$} & \multicolumn{2}{|c|}{ ت } & \multicolumn{2}{|c|}{$\%$} & \multicolumn{2}{|c|}{ ت } \\
\hline \multicolumn{2}{|c|}{31.1} & \multicolumn{2}{|c|}{14} & \multicolumn{2}{|c|}{68.9} & \multicolumn{2}{|c|}{31} \\
\hline \multicolumn{8}{|c|}{ العمر } \\
\hline \multicolumn{2}{|c|}{ 51- فأكثر } & \multicolumn{2}{|c|}{$50-41$} & \multicolumn{2}{|c|}{$40-31$} & \multicolumn{2}{|c|}{ 30-20 } \\
\hline$\%$ & ت & $\%$ & ت & $\%$ & ت & $\%$ & ت \\
\hline 15.5 & 7 & 44.44 & 20 & 35.5 & 16 & 4.4 & 2 \\
\hline \multicolumn{8}{|c|}{ مستوى التعليم } \\
\hline
\end{tabular}




\begin{tabular}{|c|c|c|c|c|c|c|c|}
\hline \multicolumn{2}{|c|}{ عليا } & \multicolumn{2}{|c|}{ بكالوريوس } & \multicolumn{2}{|c|}{ اعدادية } & \multicolumn{2}{|c|}{ متوسطة فما } \\
\hline$\%$ & ت & $\%$ & ت & $\%$ & ت & $\%$ & ت \\
\hline 15.5 & 7 & 57.7 & 26 & 17.7 & 8 & 8.8 & 4 \\
\hline
\end{tabular}

المصدر: من إعداد الباحثان في ضوء استمارة الاستبيان

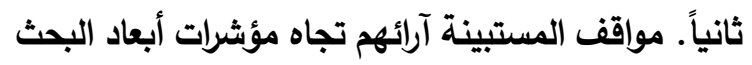

تتوضح مواقف المستبينة آراؤهم تجاه مختلف الفقرات التي احتوتها استمارة الاستبانة على النحو الآتي: 1 ـ مواقفهم تجاه مؤشرات الريادة الاستراتيجية: يعكس الجدول (3) التكرارات والأوساط الحسابية والانحرافات المعيارية لمجمل مؤشرات هذا البعد، فضلاً عن ذلك يعكس معدل هذه الأوساط ومعدل هذه الانحرافات أيضاً، اللذين بلغا (3.542) و(0.71) على التوالي. ويبدو من خلال ارتفاع أقيام هذين المعدلين أو ارتفاع أقيامهما

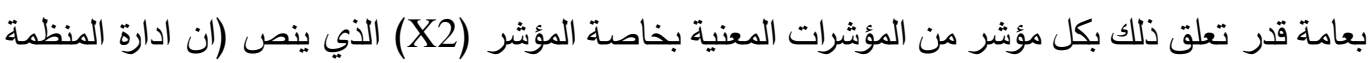

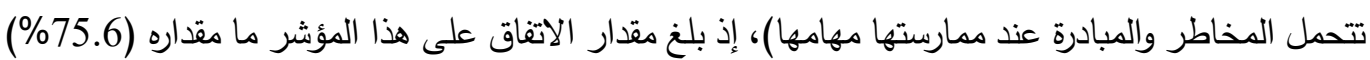

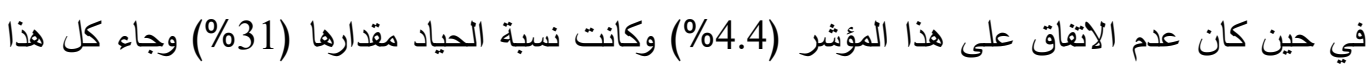
بوسط حسابي مقدار (3.777) وانحراف معياري قدره (0.635)، وإن المؤشرات المذكورة قد استحوذت على هلى اتفاق جميع المستبينة آرائهم. 


\begin{tabular}{|c|c|c|c|c|c|c|c|c|c|c|c|c|}
\hline \multirow{2}{*}{ الانحراف } & \multirow{2}{*}{ الوسط الحسبي } & \multicolumn{2}{|c|}{ اتفق بشدة } & \multicolumn{2}{|c|}{ اتفق } & \multicolumn{2}{|c|}{ محايد } & \multicolumn{2}{|c|}{ لا اتفق } & \multicolumn{2}{|c|}{ لا اتفق بشدة } & \multirow{2}{*}{ الفقرة } \\
\hline & & $\%$ & $ت$ & $\%$ & 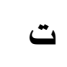 & $\%$ & 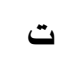 & $\%$ & ت & $\%$ & ت & \\
\hline \multicolumn{13}{|c|}{ الثقافة الريادية } \\
\hline 0.484 & 644 & - & - & 64.4 & 29 & 35.6 & 16 & 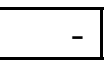 & 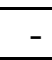 & - & & $\mathrm{X} 1$ \\
\hline 0.635 & 3.777 & 6.7 & 3 & 68.9 & 31 & 20 & 9 & 4.4 & 2 & - & - & $\mathrm{X} 2$ \\
\hline 0.659 & 3.444 & 2.2 & 1 & 46.7 & 21 & 44.4 & 20 & 6.7 & 3 & - & & X3 \\
\hline 0.777 & 3.622 & 1.1 & 5 & 46.7 & 21 & 35.6 & 16 & 6.7 & 3 & - & - & $\mathrm{X4}$ \\
\hline 0.626 & 3.488 & - & - & 55.6 & 25 & 37.8 & 17 & 6.7 & 3 & - & - & X5 \\
\hline 0.719 & 3.400 & 2.2 & 1 & 44.4 & 20 & 46.7 & 21 & 4.4 & 2 & 2.2 & 1 & $\mathrm{X6}$ \\
\hline \multicolumn{13}{|c|}{ القيادية الريادية } \\
\hline 0.564 & 3.666 & 4.4 & 2 & 57.8 & 26 & 37.8 & 17 & - & - & - & - & $\mathbf{X 7}$ \\
\hline 0.656 & 3.577 & 2.2 & 1 & 60 & 27 & 31.1 & 14 & 6.7 & 3 & - & - & $\mathrm{X8}$ \\
\hline 0.814 & 3.466 & 8.9 & 4 & 37.8 & 17 & 46.7 & 21 & 4.4 & 2 & 2.2 & 1 & X9 \\
\hline 0.852 & 3.333 & 4.4 & 2 & 40 & 18 & 44.4 & 20 & 6.7 & 3 & 4.4 & 2 & X10 \\
\hline 0.786 & 3.488 & 2.2 & 1 & 57.8 & 26 & 28.9 & 13 & 8.9 & 4 & 2.2 & 1 & X11 \\
\hline \multicolumn{13}{|c|}{ التفكير الريادي } \\
\hline 0.726 & 3.533 & 4.4 & 2 & 53.3 & 24 & 33.3 & 15 & 8.9 & 4 & - & - & $\mathrm{X} 12$ \\
\hline 0.716 & 3.622 & 6.7 & 3 & 55.6 & 25 & 31.1 & 14 & 6.7 & 3 & - & - & $\mathbf{X 1 3}$ \\
\hline 0.805 & 3.377 & 8.9 & 4 & 31.1 & 14 & 48.9 & 22 & 11.1 & 5 & - & - & X14 \\
\hline 0.726 & 3.511 & 6.7 & 3 & 44.4 & 20 & 42.2 & 19 & 6.7 & 3 & - & - & $\mathrm{X} 15$ \\
\hline 0.694 & 3.466 & 4.4 & 2 & 44.4 & 20 & 44.4 & 20 & 6.7 & 3 & - & - & $\mathrm{X} 16$ \\
\hline 0.814 & 3.466 & 6.7 & 3 & 46.7 & 21 & 33.3 & 15 & 13.3 & 6 & - & - & $\mathbf{X 1 7}$ \\
\hline \multicolumn{13}{|c|}{ الادارة الإستراتيجية للموارد } \\
\hline 0.608 & 3.755 & 6.7 & 3 & 64.4 & 29 & 26.7 & 12 & 2.2 & 1 & - & - & $\mathrm{X18}$ \\
\hline 0.842 & 3.533 & 4.4 & 2 & 60 & 27 & 22.2 & 10 & 11.1 & 5 & 2.2 & 1 & $\mathbf{X 1 9}$ \\
\hline 0.743 & 3.644 & 6.7 & 3 & 57.8 & 26 & 31.1 & 14 & 2.2 & 1 & 2.2 & 1 & $\mathrm{X} 20$ \\
\hline 0.757 & 3.511 & 4.4 & 2 & 51.1 & 23 & 37.8 & 17 & 4.4 & 2 & 2.2 & 1 & X21 \\
\hline 0.626 & 3.488 & - & - & 55.6 & 25 & 37.8 & 17 & 6.7 & 3 & - & - & $\mathrm{X22}$ \\
\hline 0.707 & 3.666 & 8.9 & 4 & 53.3 & 24 & 33.3 & 15 & 4.4 & 2 & - & - & $\mathbf{X 2 3}$ \\
\hline 0.71 & 3.542 & \multicolumn{2}{|c|}{4.92} & \multicolumn{2}{|c|}{52.08} & \multicolumn{2}{|c|}{36.15} & \multicolumn{2}{|c|}{6.08} & \multicolumn{2}{|r|}{0.77} & المعدل العام \\
\hline
\end{tabular}

المصدر : من إعداد الباحثان في ضوء نتائج الحاسبة الاككترونية .

2. مواقفهم تجاه مؤشرات البراعة التسويقية: يعكس الجدول (4) التكرارات والأوساط الحسابية والاتحرافات المعيارية لمجمل مؤشرات هذا البعد، فضلاً عن ذلك يعكس معدل هذه الأوساطومعدل هذه الانحرافات أيضاً، اللذين بلغا (3.543) و(0.763) على التوالي. ويبدو من خلال ارتفاع أقيام هذين المعدلين أو ارتفاع أقيامهما

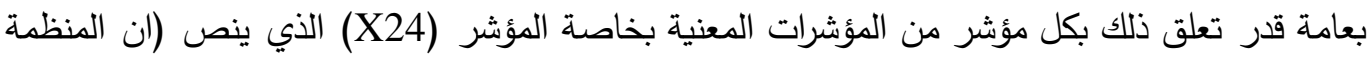

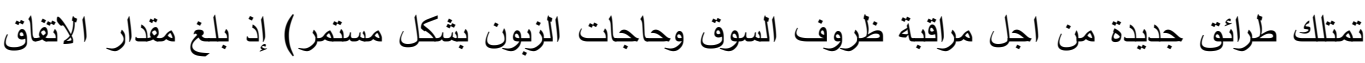


على هذا المؤشر ما مقداره (62.2\%) في حين كان عدم الاتفاق على هذا المؤشر (2.2\%) وكانت نسبة الحياد مقدارها (35.6\%) وجاء كل هذا بوسط حسابي مقداره (3.688) وانحراف معياري قدره (0.668)، وإن المؤشرات المذكورة قد استحوذت على اتفاق جميع المستبينة آرائهم.

الجدول (4): مواقف المستبينة أراؤهم من مؤشرات البراعة التسويقية

\begin{tabular}{|c|c|c|c|c|c|c|c|c|c|c|c|c|}
\hline \multirow{2}{*}{ الانحراف } & \multirow{2}{*}{ الكسابي } & \multicolumn{2}{|c|}{ |تفق بشدة } & \multicolumn{2}{|c|}{ اتفق } & \multicolumn{2}{|c|}{ محايد } & \multicolumn{2}{|c|}{ لا اتفق } & \multicolumn{2}{|c|}{ لا اتفق بثدة } & \multirow{2}{*}{ المتفيرات } \\
\hline & & $\%$ & $ت$ & $\%$ & $ت$ & $\%$ & $ت$ & $\%$ & $ت$ & $\%$ & $ت$ & \\
\hline \multicolumn{13}{|c|}{ استكشاف الفرص } \\
\hline 0.668 & 3.688 & 8.9 & 4 & 53.3 & 24 & 35.6 & 16 & 2.2 & 1 & - & - & $\mathrm{X} 24$ \\
\hline 0.724 & 3.555 & 6.7 & 3 & 48.9 & 22 & 37.8 & 17 & 6.7 & 3 & - & - & $\mathrm{X} 25$ \\
\hline 0.738 & 3.666 & 13.3 & 6 & 42.2 & 19 & 42.2 & 19 & 2.2 & 1 & - & - & X26 \\
\hline 0.815 & 3.488 & 8.9 & 4 & 42.2 & 19 & 37.8 & 17 & 11.1 & 5 & - & - & X27 \\
\hline 0.84 & 3.444 & 11.1 & 5 & 31.1 & 14 & 51.1 & 23 & 4.4 & 2 & 2.2 & 1 & $\mathrm{X} 28$ \\
\hline 0.694 & 3.466 & 2.2 & 1 & 51.1 & 23 & 37.8 & 17 & 8.9 & 4 & - & - & $\mathrm{X} 29$ \\
\hline \multicolumn{13}{|c|}{ استغلال الفرص } \\
\hline 0.848 & 3.311 & 2.2 & 1 & 44.4 & 20 & 40 & 18 & 8.9 & 4 & 4.4 & 2 & X30 \\
\hline 0.694 & 3.488 & 4.4 & 2 & 46.7 & 21 & 42.2 & 19 & 6.7 & 3 & - & - & X31 \\
\hline 0.757 & 3.488 & 4.4 & 2 & 51.1 & 23 & 33.3 & 15 & 11.1 & 5 & - & - & X32 \\
\hline 0.786 & 3.533 & 8.9 & 4 & 44.4 & 20 & 37.8 & 17 & 8.9 & 4 & - & - & X33 \\
\hline 0.645 & 3.644 & 6.7 & 3 & 53.3 & 24 & 37.8 & 17 & 2.2 & 1 & - & - & X34 \\
\hline 0.814 & 3.533 & 6.7 & 3 & 51.1 & 23 & 33.3 & 15 & 6.7 & 3 & 2.2 & 1 & $\mathrm{X} 35$ \\
\hline \multicolumn{13}{|c|}{ المرونة التسويقية } \\
\hline 0.833 & 3.622 & 8.9 & 4 & 55.6 & 25 & 26.7 & 12 & 6.7 & 3 & 2.2 & 1 & X36 \\
\hline 0.645 & 3.644 & 2.2 & 1 & 66.7 & 30 & 24.4 & 11 & 6.7 & 3 & - & - & X37 \\
\hline 0.756 & 3.466 & 4.4 & 2 & 48.9 & 22 & 35.6 & 16 & 11.1 & 5 & - & - & X38 \\
\hline 0.893 & 3.444 & 4.4 & 2 & 53.3 & 24 & 28.9 & 13 & 8.9 & 4 & 4.4 & 2 & X39 \\
\hline 0.825 & 3.666 & 11.1 & 5 & 53.3 & 24 & 28.9 & 13 & 4.4 & 2 & 2.2 & 1 & $\mathrm{X} 40$ \\
\hline 0.773 & 3.644 & 13.3 & 6 & 42.2 & 19 & 40 & 18 & 4.4 & 2 & - & - & $\mathrm{X} 41$ \\
\hline 0.763 & 3.543 & \multicolumn{2}{|c|}{7.15} & \multicolumn{2}{|c|}{48.9} & \multicolumn{2}{|c|}{36.18} & \multicolumn{2}{|c|}{6.79} & \multicolumn{2}{|c|}{0.98} & المعدل العام \\
\hline
\end{tabular}

المصدر : من إعداد الباحثان في ضوء نتائج الحاسبة الالكترونية . ثالثاً. اختبار فرضيات البحث : من إعداد وتتحدد فرضيات هذا البحث بالفرضيات الآتية : 1. الفرضية الرئيسة الأولى: تنص هذه الفرضية (لا تتحس البراعة التسويقية تجاه الريادة الاستراتيجية في المنظمة المبحوثة)، تم اختبار هذه الفرضية وذلك من خلال اختبار الحساسية Sensitivity والفاعلية Specificity ، إذ توضح معطيات الجدول (5) أن هناك فعالية ما بين الريادة الاستراتيجية والبراعة التسويقية وبنسبة (78.1\%) مما يثير إلى أن المنظمة المبحوثة تقوم بتعزيز البراعة التسويقية بناءً على الريادة الاستراتيجية التي تثهدها تلك المنظمة ، بينما بلغت نسبة التحس بين البعدين 
(38.4\%) ، حيث أثرت على هذه النسبة عوامل أخرى لم تدخل في البحث، عليه ترفض الفرضية

$$
\text { الأولى وتقبل الفرضية البديلة . }
$$

الجدول (5): نتائج اختبار Sensitivity \& Specificity للعلاقة بين الريادة الاستراتيجية والبراعة التسويقية

\begin{tabular}{|c|c|c|c|c|}
\hline & & \multicolumn{2}{|c|}{ الريادة } & \multirow{2}{*}{ Total } \\
\cline { 3 - 5 } & & Yes (1) & No (0) & \\
\hline \multirow{3}{*}{} & Yes (1) & 5 & 7 & 12 \\
\cline { 2 - 5 } & No (0) & 8 & 25 & 33 \\
\cline { 2 - 5 } & Total & 13 & 32 & 45 \\
\hline
\end{tabular}

Sensitivity test: $(5 / 13) * 100=\% 38.4-1$

Specificity test: $(25 / 32) * 100=\% 78.1-2$

المصدر: الباحثان بالاعتماد على نتائج البرنامج الإحصائي :SPSS.

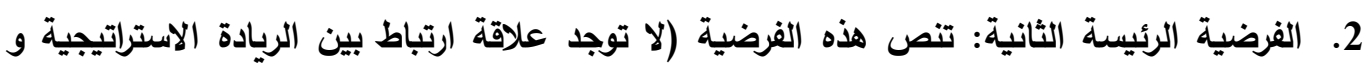

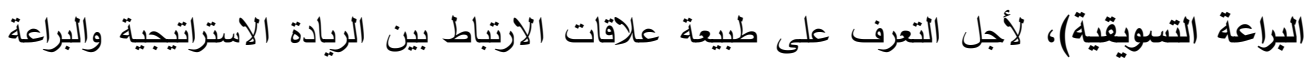
التسويقية تثير معطيات الجدول (6) إلى وجود علاقة ارتباط معنوية موجبة إذ بلغت قيمة معامل

$$
\text { الارتباط الكلي (0.713) عند مستوى معنوية قدره (0.05). }
$$

\begin{tabular}{|c|c|}
\hline البراعة التسويقية & البعد المعتمد \\
\hline$(0.713)^{* *}$ & الريادة الاستراتيجية \\
\hline
\end{tabular}

الجدول (6): معامل الارتباط بين الريادة الاستراتيجية والبراعة التسويقية علدية

المصدر : من إعداد الباحثان في ضوء نتائج الحاسبة الالكترونية .

ويتفرع من الفرضية الرئيسة الثانية الفرضية الفرعية الاتية (لا توجد علاقة ارتباط بين ابعاد متغير

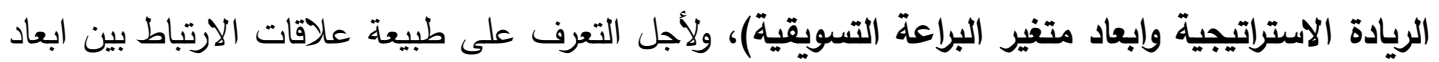
متغير الريادة الاستراتيجية وابعاد متغير البراعة التسويقية يشير الجدول (7) إلى علاقات الإديه الارتباط بينهم .

الجدول (7): معامل الارتباط بين ابعاد الريادة الاستراتيجية وابعاد البراعة التسويقية 


\begin{tabular}{|c|c|c|c|}
\hline التسويقية & الفتغلال & استكثاف الفرص & المتغير المعتمد المتغير المستقل \\
\hline $0.325^{*}$ & 0.156 & $0.502 * *$ & الثقافة الريادية \\
\hline $0.422 * *$ & $0.509 * *$ & $0.377^{*}$ & القيادة الريادية \\
\hline $0.509 * *$ & $0.401 * *$ & $0.506^{* *}$ & التفكير الريادي \\
\hline $0.614 * *$ & $0.491 * *$ & $0.777^{*}$ & الادارة الاستراتيجية للموارد \\
\hline
\end{tabular}

المصدر: من إعداد الباحثان في ضوء نتائج الحاسبة الالكترونية.

في ضوء نتائج معطيات الجدول (7) لوحظ ان اعلى قيمة علاقة ارتباط بين الادارة الإستراتيجية للموارد واستكثاف الفرص بقيمة ارتباط مقدارها (0.777)، في حين كانت اقل قيمة علاقة ارتباط بين الثقافة الريادية

واستغلال الفرص بقيمة ارتباط مقدارها (0.156)، وكانت بقية علاقات الارتباط واقعة بين القيمتين اعلاه. عليه ... ووفق ما تم ذكره اعلاه نلاحظ وجود علاقة ارتباط بين ابعاد متغير الريادة الاستراتيجية وابعاد متغير البراعة التسويقية، لذا ترفض الفرضية الفرعية وتقبل الفرضية البديلة. 3. الفرضية الرئيسة الثالثة: والتي تتص (لا توجد علاقة اثر بين الريادة الاستراتيجية والبراعة التسويقية في المنظمة المبحوثة)، تثير نتائج الجدول(8) إلى التحليل المعنوي بين الريادة الاستراتيجية والبراعة

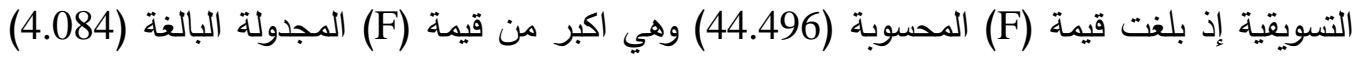
عند درجتي حرية (43،1) ومستوى معنوية (0.05)، وكانت قيمة معامل التحديد (R) هي (R) هي (0.713)، التي تثير إلى أن نسبة الاختلاف المفسر في البراعة التسويقية في المنظمة المبحوثة بسبب تأثير الريادة الاستراتيجية لا تقل عن(71.3\%) والنسبة المتبقية والبالغة (28.7\%) تمثل نسبة مساهمة المتغيرات غير فير لئه المبحوثة، ويستدل من قيمة (م) البالغة واختبار (T) لها أن تأثير الريادة الاستراتيجية على البراعة التسويقية كان قدره (0.86) وبدلالة قيمة (T) المحسوبة (6.67) والتي هي قيمة معنوية وكذلك اكبر من قيمتها الجدولية البالغة (1.684) والتي تعكس طبيعة إجابات المبحوثين عن قدرتهم في تقسير تأثير الريادة

$$
\text { الاستراتيجية على البراعة التسويقية. }
$$

من خلال ما تقدم وفي ضوء المعطيات السابقة تبين ان هناك علاقة اثر بين الريادة الاستراتيجية والبراعة التسويقية، لذا ترفض الفرضية الرئيسة الثالثة وتقبل الفرضية البديلة . 
الجدول (8): علاقة الأثر بين الريادة الاستراتيجية والبراعة التسويقية

\begin{tabular}{|c|c|c|c|c|c|}
\hline \multicolumn{5}{|c|}{ البراعة التسويقية } & \multirow{3}{*}{ البعد المعتمد البعد المستقل } \\
\hline \multirow{2}{*}{$\boldsymbol{\beta}$} & \multicolumn{2}{|c|}{$\mathbf{F}$} & \multirow{2}{*}{ D.F } & \multirow{2}{*}{$\mathbf{R}^{2}$} & \\
\hline & الجدولية & المحسوبـة & & & \\
\hline $\begin{array}{c}0.86 \\
(6.67)\end{array}$ & 4.084 & 44.496 & $\begin{array}{c}1 \\
43 \\
\end{array}$ & 0.713 & الريادة الاستراتيجية \\
\hline
\end{tabular}

المصدر: من إعداد الباحثان في ضوء نتائج الحاسبة الالكترونية

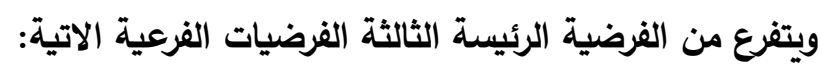

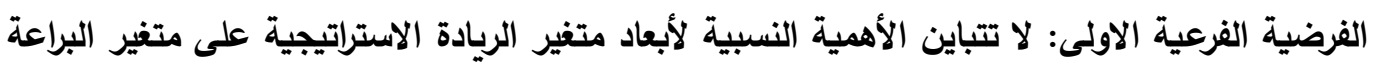

$$
\text { التسويقية في المنظمة المبحوثة " . }
$$

للتحقق من صحة الفرضية الفرعية الاولى من الفرضية الرئيسة الثانية تفصح معطيات الجدول (9) عن

أ. التي: دخل بعد الادارة الإستراتيجية للموارد في المرحلة الأولى باعتباره من أكثر المتغيرات أهمية، اذ كانت

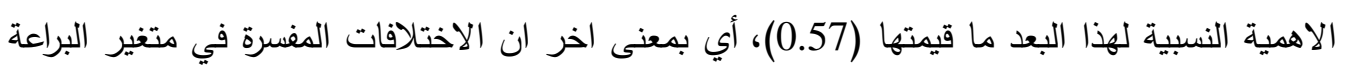

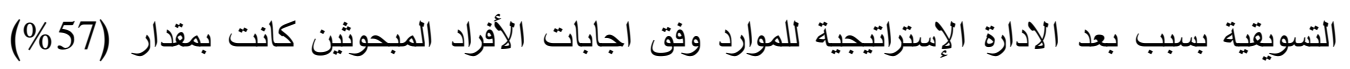
وبدلالة قيمة معامل م (0.72) وبدلالة T المحسوبة البالغة (7.543) وهي أكبر من قيمتها الجدولية

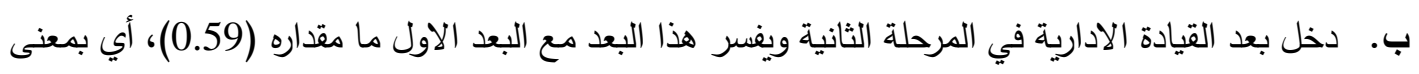

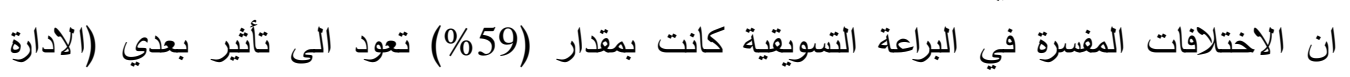

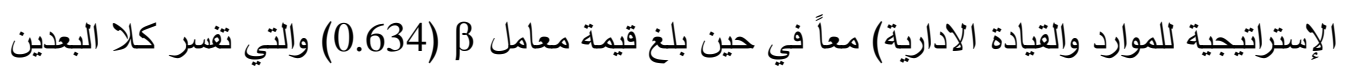
معا وبدلالة T المحسوبة البالغة(5.652) وهي أكبر من قيمتها الجدولية (1.684).

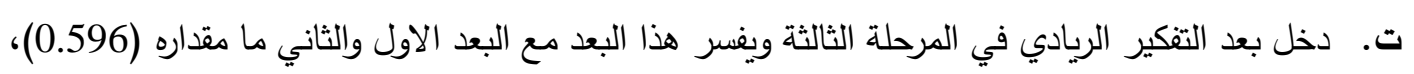

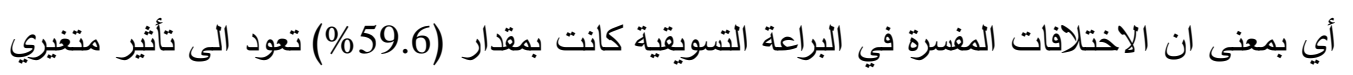

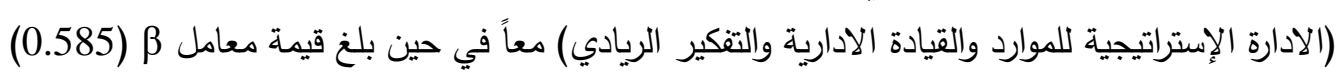

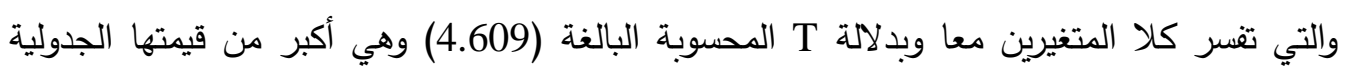

ث. دخل بعد الثقافة الريادية في المرحلة الاخيرة ويفسر هذا البعد مع كل من الابعاد الثلاثة السابقة ما مقداره

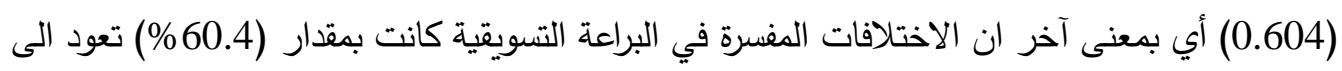

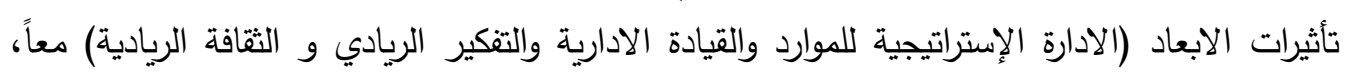


وكانت قيمة معامل ß هي (0.655) وبدلالة T المحسوبة البالغة (4.355) وهي أكبر من قيمتها الجدولية

عليه..... ووفق ما تم ذكره أعلاه فان الأهمية النسبية لأبعاد الريادة الاستراتيجية تختلف من بعد إلى آخر

لذلك ترفض الفرضية الفرعية وتقبل الفرضية البديلة.

الجدول (9): الأهمية النسبية لتأثير ابعاد الريادة الاستراتيجية على البراعة التسويقية لإنية

\begin{tabular}{|c|c|c|c|c|c|c|}
\hline \multirow{2}{*}{ المرحلة } & \multirow{2}{*}{ D.F } & \multicolumn{2}{|c|}{ T. Value } & \multirow{2}{*}{ B } & \multirow{2}{*}{ الاهمية } & \multirow[b]{2}{*}{ المتغيرات } \\
\hline & & 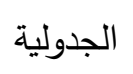 & 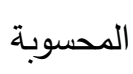 & & & \\
\hline 1 & $\begin{array}{c}1 \\
43\end{array}$ & \multirow{4}{*}{1.684} & 7.543 & 0.72 & 0.57 & الادارة الإستراتيجية للموارد \\
\hline 2 & $\begin{array}{c}2 \\
42\end{array}$ & & 5.652 & 0.634 & 0.59 & الادارة الإستراتيجية للموارد + القيادة الادارية \\
\hline 3 & $\begin{array}{c}3 \\
41\end{array}$ & & 4.609 & 0.585 & 0.596 & الادارة الإستراتيجية للموارد + القيادة الادارية \\
\hline 4 & $\begin{array}{c}4 \\
40\end{array}$ & & 4.355 & 0.655 & 0.604 & الادارة الإستراتيجية للموارد + القيادة الادارية \\
\hline
\end{tabular}

$\mathrm{N}=45$

عند مستوى معنوية (0.05)

المصدر: من إعداد الباحثان في ضوي ندوبة نائج الحاسبة الالكترونية. المحور الرابع: الاستنتاجات والمقترحات

أولاً. الاستنتاجات

1. ان تبني الريادة الإستراتيجية يؤدي إلى قيام المنظمات بتسليط الضوه على الفجوة المعرفية وذلك من خلال

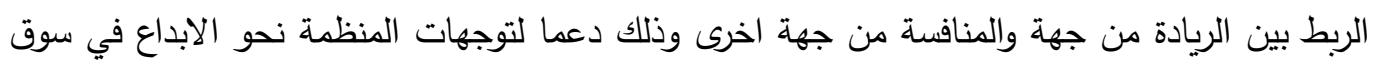

2. يوجد اهتمام في المنظمة المبحوثة بالبراعة التسويقية بأبعادها (الاستكثاف والاستغلال والمرونة)، وهذا يدل

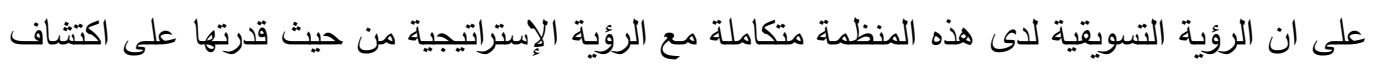
واستغلال الفرص التسويقية في ضوء المرونة التسويقية التي تتمتع بها. 3. في ضوء نتائج وصف متغيرات وابعاد البحث ومن وجهة نظر الافراد المبحوثين لوحظ وجود اتفاق عام من

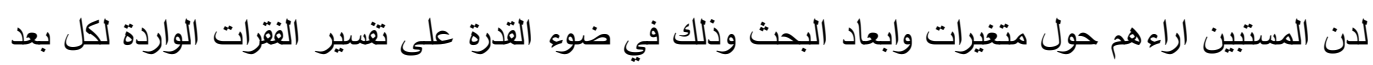
من ابعاد البحث وهذا يعطي صورة ايجابية عن المعرفة التي تمتلكها هذه العينة. 4. من خلال ما تم ملاحظته في الجانب الميداني للبحث لوحظ وجود تحس للبع للبراعة التسويقية تجاه الريادة الإستراتيجية، وان هناك علاقات ارتباط وتأثير بين المتغيرين سواءً على المستوى الاجمالي ام على مستوى 
الابعاد، وكذلك لوحظ ان أكثر الابعاد اهمية بالنسبة لأبعاد متغير الريادة الإستراتيجية على متغير البراعة

$$
\begin{aligned}
\text { ثانياً. المقترحات التسويقية هو الادارة الإستراتيجية للموارد. } &
\end{aligned}
$$

1. ضرورة قيام المنظمة المبحوثة بشكل خاص والمنظمات بثكل عام على نشر ثقافة الريادة سوآءا على

مستواها الاستراتيجي ام على مستوى وحدات الاعمال لما لها من اهمية في رفع المستوى التنافسي للمنظمة.

2. ضرورة قيام المنظمات بتخصيص جزء من مواردها المالية للقيام بدورات تطويرية ام تدربية للأفراد العاملين

لديها وذلك دعما لزيادة التفكير الابداعي لديهم مما ينعكس ايجابا على ادائهم لأعمالهم في منظماتهم.

3. ضرورة قيام المنظمات بالاهتمام بالبراعة التسويقية من خلال استكثاف واستغلال الفرص التسويقية المتاحة

امامها أو خلق (توليد / انثاء) فرص تسويقية خاصة بها وايلاء الاهتمام بالمرونة التسويقية والتي هي من

السمات المهمة والمميزة لمنظمات الاعمال التي تحاكي الواقع المتغير في البيئة.

4. تعزيز الاهتمام بعمليات استثمار للفرص التسويقية من خلال استكثاف هذه الفرص واستغلالها وذلك دعما

لتعزيز مستوى البراعة التسويقية في ضوء المتغيرات التي تثهدها المنظمات والتي يمكن ان تحاكيها بتبنيها

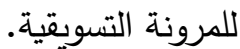

$$
\begin{aligned}
& \text { 5. في إطار الدراسات المستقبلية فان الباحثان يقترحان العناوين الاتية: } \\
& \text { • مدى توافر ابعاد الريادة الإستراتيجية لمنظمة انتاجية مختارة. } \\
& \text { • المرونة التسويقية ودورها في تحقيق الاستجابة التسويقية للمنظمات الخدمية. }
\end{aligned}
$$

\section{References}

Abu Joyfel, Reem Jumaa. 2018, The degree of practicing the Faculties of Education in Palestinian universities in the governorates of Gaza for the dimensions of strategic leadership and its relationship to distinguished university performance [Master Thesis, Gaza University] . House system information base.

Ahmed, Maysoon Abdullah, Ismail, Muhammad Hazem, 2019, Marketing prowess and its impact on enhancing job plunge, a survey of the opinions of some administrative leaders at the University of Mosul, Tikrit Journal of Administrative and Economic Sciences / Volume (15) Issue (47) C1.

Al Hasnawi, Hosni Harjieh Ghali. Al-Sanjari, Hend Adnan Hosni, 2020,) The Effect of Moral Intelligence of a Leader in Enhancing Strategic Excellence, Analytical Study of the Views of a Sample of Faculty Members in Universities and Private Colleges Operating in Babil Governorate, Journal of Administration and Economics (Volume 9) (Issue 33).

Al-AL-Hakim, Laith Ali. Ali, Ahmed Radi Mohamed. 2017, Leadership \& its Reflection in the Development of Organizations - The Independent High Electoral Commission as a Model, Al-Ghary Journal for Economic \& Administrative Sciences, Volume Fourteen, Issue (2). 
Al-Ani, Alaa Abd al-Muawjid, Hussein, Hoda Abdul-Rahim, 2018 (compatibility between big data entry and marketing prowess, an exploratory study of the opinions of a sample of managers in Asiacell Mobile Communications Company in Iraq

Al-Awda, Anhar Muhammad, 2020 AD, The Arab Journal of Scientific Publishing, the marketing prowess of government secondary school leaders from the point of view of female teachers in the Qassim region, issue twentieth.

Al-Hamad, Alaa Daham. Muhammad, Ali Ahmed. 2020, Leadership \& its Role in Performance, Journal of Economics \& Administrative Sciences, University of Baghdad, College of Management \& Economics, Baghdad-Iraq, Volume 26 (NO. 124).

Al-Mahasna, Lamis Aref Abed Rabbo. Abbas, Ali Muhammad. 2017, (the mediating role of marketing prowess in the relationship between dynamic capabilities and marketing agility, a field study on the Jordanian organizations of the pharmaceutical industries), this thesis was presented to complete the requirements for obtaining a master's degree in Business Administration, Department of Business Administration, College of Business, Middle East University, June.

Al-Mousawi, Kawthar Hamid Hani, 2018, (Strategic Agility and its Role in Achieving Marketing Excellence, An Analytical Study of the Views of a Sample of Directors in Al-Kafeel Company, University of Kufa - College of Administration and Economics.

Al-Nuaimi, Shihab Al-Din Hamad. Hamid, Reem Muhannad. 2015, High Commitment Management Requirements to Achieve Strategic Leadership in Business Organizations, Field Research in Iraqi Contracting Companies, Journal of Economic \& Administrative Sciences, Volume (21) Issue (84).

Al-Shammari,Sadiq Rashid,2015, The Role \& Dimensions of Strategic Leadership in Improving Distinguished Banking Performance, An Analytical Study in a Selected Sample of Private Iraqi Banks, Baghdad College of Economic Sciences University, Journal of Economic \& Administrative Sciences, Volume 21, Issue 83.

Al-Taha, Shihab Muhammad Mahmoud. Al-Hilali, Kalthoum Hamid Ramadan, 2020, (The extent of the contribution of strategic prowess to organizational excellence, an analytical study at the General Company for Northern Cement), Tikrit University / College of Administration and Economics / Tikrit Journal of Administrative and Economic Sciences / Volume (61) Issue (50) (C1).

Alwan, Bushra Muhammad. Al-Sultani, Saadia Haif Kazem. Khalil, Amir Ali. 2019, (The Role of Marketing Excellence in Promoting the Empowerment Strategy, a comparative analytical survey between two samples of senior bank leaders between the cities of Babylon and Karbala), Journal of the College of

TANMIYAT AL-RAFIDAIN (P-ISSN: 1609-591X; E-ISSN: 2664-276X) تنمية الرافدين 
Administration and Economics for Economic, Administrative and Financial Studies, Volume 11, Issue 2.

al-Yassiri, A. M., \& Hussein,A.A.A,2016,The effect of organizational improvisation on strategic leadership + an analytical study of the opinions of a sample of workers in private banks in the governorates of the Middle Euphrates. THE IRAQI MAGAZINJE FOR MANAGERIAL SCIENCES.

Amer, Yasser Muhammad. Sukkarr, Naji Rajab,2020,Strategic leadership of graduate studies departments in Palestinian universities, \& their relationship to the quality of educational outcomes (Doctoral dissertation,Al Aqsa University),MA Thesis, Al-Aqsa University,Gaza.

Bodwell, W \& Chermack, T. (2010). "Organizational ambidexterity: Integrating deliberate and emergent strategy with scenario planning". Technological Forecasting \& Social Change, 77 (2) .

Bryson, M; John, B; Kimberly, G \& Rainey, H. (2008). "Strategic Orientation and Ambidextrous Public Organizations". Cardiff University and the Economic and Social Research Council.

Chang, Hung-Jung \& Wang, Hsien-Bin (April 2013 ), A Case Study On The Model Of Strategic Entrepreneurship , The International Journal of Organizational Innovation Vol 5 Num 4.

Gylling ‘Catharina ، Elliott ، Richard \& Toivonen، Marja،2012،"Co-Creation Of Meaning As A Prerequisite For Market-Focused Strategic Flexibility"، European Journal Of Marketing، Vol. 46 Iss 10.

Ibrahim, Lamia Ali. Jawad, Maysa Saad. 2018, Strategic Leadership \& its Role in Achieving Creativity Components - An exploratory study on a sample in the environment of governmental \& private Iraqi banks in Karbala Governorate, Iraqi Journal of Management Sciences, Volume (15) Issue (59).

Jing ،Zhang \& Yanling، Duan، (2010)" The Impact Of Ambidexterity Of Market Orientation On New Product Performance: Evidence From Chinese Manufacturers ،Jouenal Of Science And Technology.

Mahmoud, Naji Abdul Sattar, Fadel, Salameh Manea, 2019, (The Contribution of Knowledge Sharing to Enhancing Organizational Excellence, An Exploratory Study of the Views of a Sample of Faculty Members at Tikrit and Samarra Universities),College of Administration and Economics, Tikrit University.

Rezaian,A.,Naeiji,M.J.,2012, Strategic Entrepreneurship \& Intellectual Capital as Determinants of Organizational Performance: Empirical Evidence from Iran steel Industry, Global Entrepreneurship Research, Winter \& Spring, Vol.2, No.1.

Salman, Muhammad Ibrahim. Sarsour, Jaber Ali Salmi. 2019 The strategic leadership of academic leaders \& their relationship to the quality of institutional performance at Al-Aqsa University, Al-Aqsa University, Gaza, Palestine.

TANMIYAT AL-RAFIDAIN (P-ISSN: 1609-591X; E-ISSN: 2664-276X) تنمية الرافدين 
Shabat, Jalal Ismail. Al-Masry, Nidal Hamdan. 2020, The Role of the Strategic Leadership Dimensions in Enhancing Organizational Memory (a field study on Ooredoo Palestine for Cellular Communications), Journal of the Islamic University for Economic Studies \& Management Sciences, Vol 28, No 2.

Shirokova، Galina، Vega، Gina\& Sokolova، Liubov (2013) ،"Performance Of Russian Smes: Exploration،Exploitation And Strategic Entrepreneurship"، Critical Perspectives On International Business، Vol. 9 Iss 1/2.

Spicer ‘André\& Holmqvist ‘Mikael ،(2012)" The Ambidextrous Employee: Exploiting And Exploring People's Potential" In Managing 'Human Resources' By Exploiting And Exploring People's Potentials. Published Online: 2012; 1-23.

Sultan, Hikmat Rashid, Hajji, \& Yusuf Afaq (2016) The role of strategic leadership components in achieving the dimensions of higher education quality - a field study in a sample of private universities in the Kurdistan region, Journal of the University of Human Development, Volume 2, Issue 2.

Xu,Hui ،Feng, Yongchun \& Zhou ،Lianxi،(2016)" Market Knowledge Development Of Indigenous Chinese Firms For Overseas Expansion: Insights From Marketing Ambidexterity Perspective،Journal Of Asian Businesses In A Turbulent Environment.

Yılmaz ، kurtuluş ,(2012), the response of the entrepreneurship to the chanaging business environment: strategic entrepreneurship ،International Journal of Economic \& Administrative Studies.

Zenati, Amal Mahsoub Muhammad. 2020 Development of talent management in STEM schools in Egypt in light of strategic leadership (future vision). Journal of the College of Education in Educational Sciences, Issue (44), Part (3). 